\title{
Divided Dems, United Reps: Party strategy and within-party variation in immigration attitudes
}

\author{
Sean Bock
}

Harvard University

\begin{abstract}
In an era of high partisanship, salient issues have the potential to become flashpoints for both parties. Why, then, do parties not emphasize certain hot-button issues symmetrically? This paper argues that in order to answer this question, social scientists must study attitudes at three levels: (1) the aggregate, (2) between-party, and (3) within-party. Each level provides necessary information for understanding party strategy toward issues and the broader consequences of public opinion for institutional politics. Using several waves of ANES data between 1992 and 2016, I apply this analytic strategy to immigration - one of the most salient issues in U.S. and European politics - to understand why Democrats, unlike Republicans, have not touted immigration as a central issue of the party. The results suggest that Democrats may be reluctant to run on immigration because substantial intra-party disagreement make this strategy too risky; on the other hand, touting immigration poses little risk to a uniform Republican party and provides much upside in their potential to "wedge" a divided Democratic party. I conclude by discussing the consequences of within-party variation for our understanding of party coalitions and electoral strategy.
\end{abstract}

The literature on the increased polarization of public attitudes has largely focused on trends at the aggregate and between-party levels (e.g.,DellaPosta 2020; Brooks and Manza 2013; Baldassarri and Gelman 2008; DiMaggio et al. 1996; McCarty et al. 2008; Abramowitz 2013; Layman et al. 2006). Population-level attitudinal change and partisan sorting have important implications for institutional politics. For instance, trends at each of these levels suggest certain party strategies on particular issues: If issue A is trending with increased favorability in the aggregate, we might expect both Democrats and Republicans to champion positions in line with growing public support for issue A; if issue A has become increasingly sorted along partisan lines, then we would expect both parties to make this issue a flash point in campaigns (De Sio and Weber 2014). Given increased partisan sorting across all issue domains (Baldassarri and Gelman 2008; McCarty et al. 2008; Abramowitz 2013; Layman et al. 2006)), in principle, any issue could become salient for both parties. Why, then, do some issues not become equally touted by both parties in an era of high partisanship?

I argue here that in order to fully understand how issues play out in the political arena and how parties strategize on those issues, social scientists must study attitudinal trends at three levels: 1) the aggregate, 2) between political parties, and 3) within parties. Each 
level provides necessary information for effectively understanding party strategies. While the existing literature on public attitudes and partisanship has largely focused on the first two levels, I emphasize the importance of the third level, within-party, here. Within-party variation has several implications for our understanding of institutional politics and, more specifically, issue ownership by parties. For example, if party members are clearly divided on an issue, it may be difficult for the party to establish a clear position, and the party may shy away from making said issue a focal point in campaigns; in contrast, substantial partisan uniformity on an issue allows parties to articulate clear positions in campaigns, capturing the support of party members and potential defectors of other parties in elections (Hillygus and Shields 2009). Further, clear divides within a party on a politically salient issue may serve as a harbinger of future realignment.

There has been arguably no greater hot-button issue than immigration in recent U.S. elections, as well as in Western European politics (Dennison and Geddes 2019). Not only is immigration important for its clear policy implications, but it has been the main issue for radial right parties (Dennison and Geddes 2019; Dahlström and Sundell 2012). Given immigration's political salience, we would expect both Democrats and Republicans to champion clear positions on it and make it a focal point of their respective platforms. While Republicans have effectively incorporated immigration into the center of their party's platform in recent elections (e.g., Donald Trump ran, and in part won, on an explicit anti-immigrant platform in his 2016 election campaign (Bonikowski et al. 2019; Sides et al. 2018; Lamont et al. 2017), Democrats have largely shied away from the issue. Why have Democrats, unlike Republicans, not seized on immigration?

To answer this question, I employ the analytical framework outlined above. Using several waves of American National Elections Studies (ANES) data, I evaluate trends in immigration attitudes at three levels: aggregate, between-party, and within-party. While immigration attitudes have become slightly more pro-immigration over the last several decades, there has been drastic party polarization on this issue since 2008, with Democrats becoming more pro-immigration and Republicans becoming increasingly anti-immigration. These trends at the aggregate and between-party levels suggest that immigration should be an issue taken up by both parties. Why then have Democrats not championed immigration? My analysis of within-party heterogeneity demonstrates that while the parties have clearly grown apart, the attitudes within the parties have not trended uniformly. Indeed, while Democrats have become more pro-immigration over the last several years, they have also grown more variable on this issue. A decomposition of the within-party trends shows the growing divide among Democrats can be explained by emergent ideological and partisan cleavages, with liberals and "strong" Democrats largely driving the party's pro-immigration trends. In contrast, Republicans have become more anti-immigration and consistently so. While there were previously significant differences among Republicans along regional, religious, and racial lines, these difference have collapsed, and the result is a largely uniform Republican party on immigration. The results suggest that the Democratic party has not been able to champion immigration as a central party position because considerable within-party variation exists on this issue, making a strong emphasis on immigration risky. Conversely, Republicans have been able to run and win on immigration because they have become a party of increasingly consistent and strong anti-immigration sentiment.

The contribution of this paper is both substantive and methodological. Substantively, I 
put forth a research program that emphasizes studying attitudes at multiple levels, giving researchers the ability to effectively understand how parties will strategize around certain issues and how those issues will play out in the political arena. Aggregate and between-party trends cannot explain why some issues become flash points for both parties and some issues do not show symmetry, as is the case with immigration - the polarization literature suggests that both parties will take up these issues. Methodologically, in measuring the sources of within-party variation, I develop a measure called weighted $\kappa^{\prime}$ (a reconfigured version of the kappa measure used by Manza and Brooks [1999] and others). This measure serves as a simple and interpretable measure of the dispersion among several categories in a variable of interest, while controlling for the sizes of each category. It is ideal for plotting overtime trends and making comparisons across several outcomes. The analytical approach and methodological tools supplied herein could be applied to any attitudinal outcome of interest. More broadly, this paper aims to make strides in the incorporation of institutional politics and political parties into sociology (Mudge and Chen 2014), topics largely understudied by political sociologists in recent decades.

\section{Background}

\section{Political polarization and partisan sorting}

There is a large and growing literature on political polarization-growing divides between Democrats and Republicans - in the United States and its various causes and effects (e.g., DellaPosta 2020; Baldassarri and Gelman 2008; Brooks and Manza 2013; McCarty et al. 2008; Bonikowski et al. 2019; Abramowitz 2013; Layman et al. 2006; DiMaggio et al. 1996). While "polarization" in the U.S. has become an oft-discussed topic in social science and public discourse, it is not a new phenomenon. Indeed, parties have always been deeply divided on key issues. What is new, however, is the multitude of issues on which the parties disagree; Democrats and Republicans have become increasingly divided along all major issue domains, such as race, culture, social welfare (Layman et al. 2006), and even foreign policy (Berinsky 2009).

Using roll-call voting records and data, political scientists have documented growing polarization among politicians at both the national (McCarty et al. 2009) and state levels (Shor and McCarty 2011). Party activists have also been shown to be increasingly polarized along ideological lines. While there is consensus on polarization among political elites, there is more disagreement on whether or not the electorate is polarizing (Baldassarri and Gelman 2008; Fiorina and Abrams 2009; Hare et al. 2015; Noel 2013; DiMaggio et al. 1996); a more accurate description of what has happened is that the electorate has become better sorted along ideological lines (DellaPosta 2020; Baldassarri and Gelman 2008; Fiorina and Abrams 2009; Abramowitz and Saunders 1998); that is, liberal Americans have increasingly aligned with the Democratic party and conservative Americans have increasingly aligned with the Republican party. So, rather than there being an ideological shift where Democrats are becoming more liberal and Republicans are becoming more conservative, liberals and conservatives have increasingly selected into their respective parties, resulting in a more liberal Democratic party and a more conservative Republican party. 
While pundits often point to more recent phenomena (e.g., the rise of partisan media; the Tea-Party movement), evidence suggests that the traces of the current levels of polarization go back to the 1970s and are likely the result of larger historical processes, stemming from events such as the post-Civil Rights realignment and increased economic inequality (McCarty et al. 2008). Furthermore, parties developed more distinct ideologies during this same period, giving Americans a clearer basis on which to select their political affiliation based on ideology (Noel 2013).

The current trends in polarization and partisan sorting have clear consequences for democratic processes. For example, polarization among politicians leads to lower capacity to govern, lower productivity in legislation, and slower judicial appointments (Layman et al. 2006). Furthermore, a polarized electorate has created an environment in which Americans have increasingly prejudiced views of affiliates of the opposing party - Democrats are increasingly likely to villainize Republicans and vice versa (Mason 2015).

Partisan sorting has further implications for our understanding of parties' strategies in campaigns. Given polarization across all issue domains, there is the potential for virtually any issue to become a flash point for parties, serving as an effective, low-risk means of rallying their bases (De Sio and Weber 2014). Thus, in an era of high partisanship, we would expect salient issues to become equally touted by each party. Why, then, do some salient issues not receive symmetrical emphasis by parties in campaigns? One possible explanation lies intra-party dynamics.

\section{Toward a study of both within- and between-party variation}

Studying between-party variation in attitudes often reveals patterns masked by aggregate trends. For example, if Democrats and Republicans are polarizing on issue X over time, and they are equally moving in more favorable and unfavorable directions respectively, then attitudes on issue $\mathrm{X}$ may appear stable over time in the aggregate (assuming equal numbers of Republicans and Democrats). However, just as in studying partisan sorting is essential to understanding variation underlying aggregate trends, variation within parties is missed by simply studying partisan sorting. In other words, the partisan sorting literature tends to treat parties as homogeneous groups and underlying within-party variation goes unmeasured. While Democrats and Republicans may be polarizing in terms of their respective mean support for issue $\mathrm{X}$, the consistency (i.e., the variation) with which each party supports issue $\mathrm{X}$ may vary. If so, a type of asymmetrical polarization emerges where one party becomes more extreme and consistently so, and the other party becomes more extreme, but inconsistently so. How does this matter for our understanding of issue emphasis by political parties in a highly partisan era? The latter scenario suggests differing levels of risk to each party for campaigning on issue X: While party members in both parties have grown more extreme on issue $\mathrm{X}$, one party is consistent in its increasingly extreme views, and thus has little risk in turning off party members who disagree; the other party is more fractured on issue X, making a strong emphasis on issue X a risky strategy (De Sio and Weber 2014). Further, if a party is fractured on a salient issue, an opportunity emerges for the opposing party to exploit these within-party differences, making the pay-off for running on issue $\mathrm{X}$ even higher for the consistent party (Hillygus and Shields 2009).

Thus, to fully understand socio-political attitudes over time and their potential political 
consequences, social scientists must study public attitudes at three levels: First, there should be a measure of trends in the aggregate to gauge how the public has shifted on average over time. Issue positions that are increasingly popular in the aggregate serve as potential sites of political consensus, as well as common campaign points between parties (for a thorough discussion of these "valence" issues, see De Sio and Weber (2014))

Second, variation at the between-party level should be assessed. As described in the section above, party polarization has key consequences for political functioning and is likely a key source of underlying variation in the aggregate trends. For example, stable attitudinal trends in the aggregate may mask underlying variation between parties. Further, party polarization on a given salient issue would suggest symmetrical issue ownership by each party, with two clear policy platforms for voters (Noel 2013). However, studying the between-party level alone cannot explain why some salient issues do not receive symmetrical ownership and emphasis by parties.

Third, we should measure within-party trends. Treating political parties as homogeneous groups may mask underlying variation within these parties, thus obfuscating key intra-party dynamics. For instance, is a party becoming more liberal on an issue because the party is moving in that direction as a whole, or is it a faction of the party that is driving the trend? In the latter case, asymmetrical trends within parties suggest growing factions among party members on a given issue, which can be thought of as within-party cleavages. Sociologists have long been interested in social cleavages and their consequences for party coalitions and electoral outcomes. For example, Manza and Brooks (1999) demonstrated the continued importance of social cleavages, such as religion, class, and race, in U.S. national elections over the latter-half of the 20th century. Other work has examined latent cultural cleavages, such as nationalism (Bonikowski and DiMaggio 2016) and their impact on politics (Bonikowski et al. 2019). While past work has thought of cleavages as an aggregate level phenomenon, we can also think of cleavages as existing within subgroups of a population, such as within political parties. We can think of existing within-party cleavages on a given issue, then, as the sources of variation measured in a party on the whole.

It is this third level on which this article focuses. I argue that within-party variation has at least four important consequences for our understanding of socio-political attitudes and their consequences for institutional politics: (1) Just as between-party polarization causes gridlock in politics, within-party polarization can make it difficult for parties to establish a firm identity on a policy for a given issue. Further, if the issue is salient enough, these withinparty differences can cause difficulties in choosing candidates to run in electoral contests (Bawn et al. 2012; Karol 2009; Petrocik 1996). If the opposing party is in solid agreement on said issue, it will be more likely to establish a clear party stance and, potentially, win electoral contests if this issue becomes salient in the political arena (De Sio and Weber 2014; Hillygus and Shields 2009). This logic leads to the three subsequent consequences. 2) The ability to campaign on a given issue depends not only on the average support for a given issue in a party but also the consistency with which a party supports that position -if just over half of a party supports a position on an issue, but the other half strongly opposes that position (i.e., within-party polarization), running on said issue position is risky (De Sio and Weber 2014). 3) If there is considerable within-party variation on an issue, the potential exists for an opposing party candidate to run on that issue and exploit ("wedge") existing variation - existing within-party cleavages (Hillygus and Shields 2009). Following 
from this, 4) existing within-party cleavages on an issue may serve as a harbinger of future party realignment (Hillygus and Shields 2009; Manza and Brooks 1999). If clear within-party differences exist on an issue and an opposing party champions a position on that issue that is in line with a faction of the first party's members, these members may eventually realign and switch to the opposing party. While it is beyond the scope of this study to empirically assess these consequences, the theoretical groundwork laid herein may be applied to future studies.

Beyond the consequences for party strategies outlined above, intra-party dynamics in an era of high partisanship may have serious implications for policies and political culture, more broadly. As views on issues become increasingly polarized by party, issue stances and their respective policy proposals become more extreme, as well. Thus, in a two party system, the ability to block more extreme policies from being implemented depends on the ability of the opposing party to counter. If the opposing party is not able to effectively counter the extreme policy position by running on a clear oppositional platform due to the intra-party dynamics outlined above, extreme policy positions may eventually be implemented or, at the very least, dominate the rhetoric of the party in power. Depending on the issue in question, this could have dire consequences for democratic processes.

\section{Immigration: An important case}

There is perhaps no greater hot-button issue in American politics (as well in European politics [Dennison and Geddes 2019]) than immigration (Sides et al. 2018). Not only has immigration become central to U.S. politics and beyond, but it is an issue that has clear and potentially negative consequences for political systems. For instance, immigration has been shown to be the issue of radical right parties in Western Europe (Dennison and Geddes 2019) and was a key component of Donald Trump's victory in 2016 (Sides et al. 2018). Despite immigration's centrality in the political arena, Democrats have not provided a symmetrical pro-immigration counter to Republicans, thus leaving ownership of immigration to Republicans (Petrocik 1996). Given this puzzling asymmetrical emphasis by Democrats and Republicans, along with its current saliency and importance for institutional politics, immigration serves as a prime case on which to implement the research strategy outlined above. In the remainder of this section, I briefly outline the literature on immigration attitudes. I then discuss several hypotheses about U.S. immigration attitudes at the aggregate, between-party, and within-party levels.

Social science research on immigration has taken up several debates, arguing about the various predictors and consequences of immigration attitudes, with most recent work focusing on sociotropic explanations (Hainmueller and Hopkins 2014). ${ }^{1}$ While political party is routinely included as a control variable, it has been noticeably absent as a main independent variable in the immigration attitudes literature. As Hainmueller and Hopkins conclude in their 2014 Annual Review of Political Science article, "Research on immigration attitudes to date has been surprisingly divorced from research on political partisanship and ideology. The relationship between immigration attitudes and political partisanship and ideology should be

\footnotetext{
${ }^{1}$ While there has been important work done beyond the U.S. context, I focus mainly on findings that pertain to the U.S.
} 
a central issue moving forward" (Hainmueller and Hopkins 2014: 244). Since the publication of this article in 2014, there has been increased attention to the importance of politics for our understanding of immigration attitudes, largely in response to the 2016 election and the ensuing public debates surrounding immigration policy (Flores 2018, 2017; Sides et al. 2018; Mutz 2018; Bloemraad et al. 2016). For instance, Flores (2018) demonstrated that political elite signaling can influence attitudes toward immigrants.

Other work has evaluated the relationship between immigration attitudes and party affiliation more directly. Using panel data, Hajnal and Rivera (2014) provides evidence that suggests immigration attitudes can affect one's political affiliation over time, with antiimmigration attitudes leading to more conservative self-identified political affiliation. Sides et al. (2018) argued that Americans have become deeply divided on issues of identity, such as immigration, and Donald Trump won the Republican nomination, and eventually the national election, with his explicit anti-immigrant rhetoric because there was a demand for it - especially among Republicans. And thus attitudes toward immigration were one of the key deciding factors for the 2016 election, and a key dividing issue between Democrats and Republicans (Sides et al. 2018). Recent studies of trends in public polarization have also found that Democrats and Republicans have increasingly split on immigration (Blanco et al. 2020) as well as on inclusive and exclusive forms of nationalism, with Republicans becoming more exclusive and Democrats becoming increasingly inclusive (Bonikowski et al. 2019).

Clearly immigration has become a central issue to the American political arena, and there has been growing evidence that immigration attitudes have become polarized by party (Blanco et al. 2020; Sides et al. 2018; Hajnal and Rivera 2014). Given those trends, we would expect both parties to emphasize the issue symmetrically, providing clear policy alternatives to the electorate (De Sio and Weber 2014). But has this been the case?

Following two consecutive losses in presidential elections to Barack Obama in which minority-group votes played a critical role, Republican party leaders understood that a shift in strategy was needed (Sides et al. 2018). Given the electoral defeats and an increasingly diverse electorate, Republicans attempted to shift their image to be more inclusive, in hopes of capturing the votes of an increasing share of minorities. This strategy was abruptly halted with the campaign of Donald Trump in 2016 (Sides et al. 2018; Flores 2018; Lamont et al. 2017). Trump notably ran on an explicitly anti-immigration platform, using brazen rhetoric such as referring to Mexican immigrants as "rapists" and "criminals" (Flores 2018; Lamont et al. 2017). The early success of the Trump campaign in the Republican primaries drove other serious candidates, such as Ted Cruz, to follow suit in their clear anti-immigration platforms (Bonikowski et al. 2019). Going into the 2016 national elections, the Republican party had firmly adopted an anti-immigration platform with continued provocative rhetoric (Sides et al. 2018; Elliot and Altman 2015).

Was this strong anti-immigration campaign by Republicans met by an equally strong pro-immigration platform by Democrats? The short answer is "no." While Democrats made broad references to "immigration reform" (Andrews and Kaplan 2015; PBS 2016; Min Kim 2015; Karni 2015) and used boilerplate "melting pot" rhetoric (Bonikowski et al. 2019), Democrats did not provide a symmetrical counter to the anti-immigration rhetoric of Republicans; they did not become the party of "pro-immigration."

Indeed, scholars have emphasized the need for Democrats - as well as left parties in Western Europe - to take ownership of inclusivity and immigration as a necessary means to 
Figure 1: Top 100 most frequently occurring nouns in the 2016 presidential campaign speeches. Nouns related to the topic of immigration are highlighted in red.
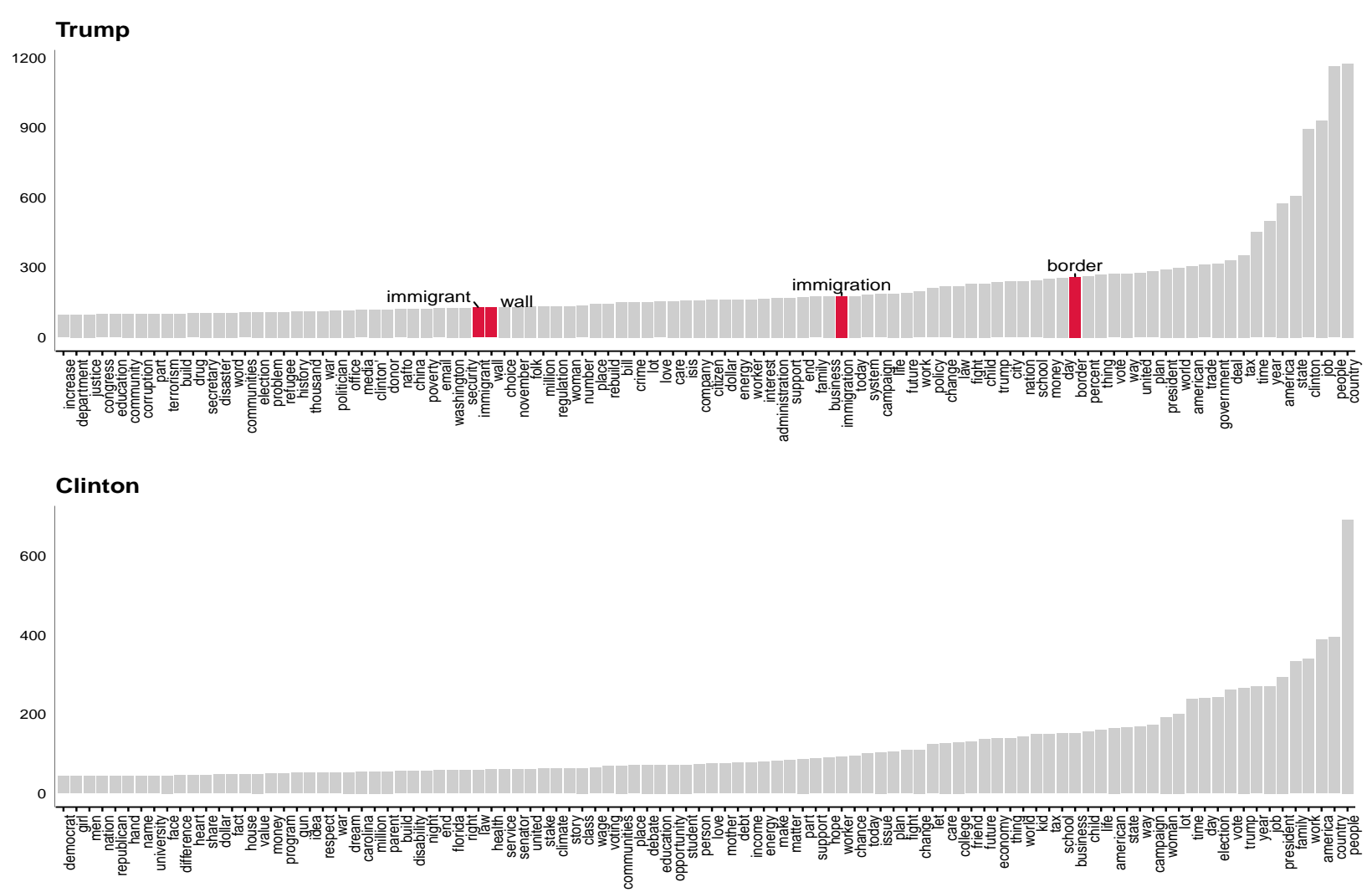
counter the increasingly extreme rhetoric and policy proposals of the right (Gidrom 2018; Dahlström and Sundell 2012). Why, then, have Democrats not taken ownership of immigration?

This papers seeks to shed light on this question by analyzing trends in immigration attitudes at three levels: 1) the aggregate, 2) between-party, and 3) within-party. As outlined above, I argue that we cannot understand the strategies of both parties on immigration (or any hot-button issue) without understanding the patterns of attitudes at each level. While there is an increasing literature on trends in immigration attitudes at the first two levels, I analyze and discuss trends at the aggregate and between-party levels as both a means to demonstrate that we cannot understand party strategy on immigration without the third level (within-party) and to replicate and confirm past findings.

\section{Hypotheses}

In light of past research on immigration attitudes and the parties' respective campaign strategies, I generate some broad expectations for the analyses at each level. Given the increased presence of explicit anti-immigration rhetoric (Sides et al. 2018; Flores 2017, 2018) in the American political arena, we might expect that there was a demand for it in the electorate (De Sio and Weber 2014). In other words, Donald Trump and the Republicans may have ridden an anti-immigration wave into office in 2016. However, despite the recent increase in exclusive politics, studies on immigration attitudes in the U.S. and abroad have not found a marked increase in anti-immigration in the aggregate but have found, rather, that the public has remained stable on immigration or even become more pro-immigration (Flores 2017; Hainmueller and Hopkins 2014). These findings lead to my first set of hypotheses concerning the aggregate level:

Hypothesis 1a (Aggregate level): Anti-immigration sentiment has risen in the aggregate.

Hypothesis $1 b$ (Aggregate level): Immigration attitudes have held steady or have become increasingly pro-immigration in the aggregate.

The partisan sorting of a wide array socio-political attitudes in the U.S. has been well established by sociologists and political scientists (e.g., Baldassarri and Gelman 2008; DiMaggio et al. 1996; Abramowitz 2013). While immigration attitudes had been largely omitted from this literature (Hainmueller and Hopkins 2014), there is now an increasing body of work that examines the relationship between partisan identification and immigration attitudes (e.g., Sides et al. 2018; Flores 2018; Hajnal and Rivera 2014). Like other attitudes across all issue domains, these studies have found that immigration has increasingly become sorted by party, with Republicans becoming more anti-immigration and Democrats becoming more pro-immigration. Moreover, recent studies have shown that nationalist beliefs have also become better sorted by party, with Democrats holding increasingly inclusive understandings of the nation and Republicans increasingly holding exclusive conceptions of the nation. These findings lead me to my hypothesis regarding the between-party level:

Hypothesis 2 (Between-party level): Immigration attitudes have become sorted by party, with Republicans becoming increasingly anti-immigration and Democrats becoming increasingly pro-immigration.

While immigration has become a hot-button issue in American politics, it has not been 
given equal emphasis by Democrats and Republicans. Republicans have made immigration a central part of their platform in recent elections, espousing explicit anti-immigration rhetoric and outlining exclusive policy proposals (Bonikowski et al. 2019; Sides et al. 2018; Flores 2018; Lamont et al. 2017), whereas Democrats have not provided a clear counter-frame on this issue. Why would Republicans take clear ownership of immigration while Democrats have shied away from it (Petrocik 1996)? Assuming parties strategically choose to emphasize some issues and deemphasize others their to advantage in the political arena, one explanation for this asymmetry on immigration is that Republicans found it advantageous to run on immigration, whereas Democrats found it too risky (De Sio and Weber 2014; Bawn et al. 2012; Hillygus and Shields 2009; Karol 2009). Under this assumption, we would expect that Republicans had support for a strong anti-immigration platform, and Democrats lacked such support for a symmetrical pro-immigration campaign (De Sio and Weber 2014). However, if immigration attitudes have become symmetrically polarized by party, and Democrats and Republicans have moved equally in opposite directions on the issue, then we would expect the same strategy by both parties. In other words, running on immigration would appear to be a sound strategy for Democrats, because immigration, like many other issues, has become strongly sorted by party; running on the issue should pose little risk and serve as an effective means of rallying the base while also countering the platform presented by Republicans.

If overall support for strong immigration campaigns is evident in both parties, why would Democrats, then, not take ownership of immigration like Republicans have? While there may appear to be support among Democrats overall, Democrats may have found it too risky to run on immigration in fear of disaffecting subsets of the party (De Sio and Weber 2014; Bawn et al. 2012). In other words, while support might have existed on average, substantial within-party variation on this issue may have made a strong immigration platform too risky. This dynamic also helps to explain the Republican strategy on immigration: In a two party system, such as in the U.S., parties run on issues not only to rally their bases, but to pick up new voters (De Sio and Weber 2014; Hillygus and Shields 2009). Parties prioritize issues for which there is support within their own party but also residual support in the electorate (i.e., support for an issue position beyond support of party members), as these issues pose little risk and maximum gain (De Sio and Weber 2014). Recognizing disagreement in the opposing party, U.S. parties emphasize "wedge issues" - highly salient and often controversial issues - in campaigns in order to exploit existing cleavages in the other party (Hillygus and Shields 2009). Thus, the strategy of using "wedge" or "bridge" issues (De Sio and Weber 2014) implies the importance of within-party variation on a given issue and not merely the mean support. In the case of immigration, then, we might expect that there is substantial variation among Democrats on immigration, whereas Republicans are consistent on the issue. This logic leads to my final hypothesis:

Hypothesis 3 (Within-party level): Variation in immigration attitudes is greater among Democrats than among Republicans.

\section{Data and Methods}

To study trends in U.S. immigration attitudes at the aggregate, between-party, and withinparty levels, I employ the cumulative time series American National Election Studies (ANES) 
datafile (The American National Election Studies 2018). This data set is a compilation of all ANES Time Series studies conducted from 1948 until the most recent wave (2016). The ANES is a commonly used dataset in social science research related to American politics and asks a variety of questions about public opinion and political identities.

Dependent variables. My key outcome of interest is attitudes toward immigration. While there are a number of measures related to this topic, I focus on the commonly used immigration policy item: "Do you think the number of immigrants from foreign countries who are permitted to come to the United States to live should be increased a lot, increased a little, left the same as it is now, decreased a little, or decreased a lot?" This item has range of 1 ("decreased a lot") to 5 ("increased a lot") and has a number of advantages compared to other immigration attitudes items: 1) it puts the focus on legal immigrants rather than illegal immigrants, which is less likely to yield negatively biased results because of the negative wording ("illegal") (Hainmueller and Hopkins 2014). 2) This item is less likely to be subject to positively biased responses because of social desirability concerns, as occurs in questions about specific groups (e.g., feeling thermometer toward Hispanics) (Hainmueller and Hopkins 2014); and 3) this item is the most widely available in ANES waves, allowing for the most robust longitudinal analysis possible. The item is available in eight waves: 1992, 1994, 1996, 1998, 2004, 2008, 2012, and 2016. A collapsed three-category version of the question (1. "decreased" 2. "stay the same" 3. "increased") was also asked in 2000. Because of this additional year and negligible impact on substantive findings, I focus on the 3-category item for analyses and visualization. ${ }^{2}$ This gives me a sample of 20,503 respondents over nine waves of ANES data.

Key independent variables. My main interest is in how immigration attitudes have been patterned by party over time. Thus my key independent variable of interest is party identification. I use the reduced three-party measure (Democrats, Independents, and Republicans). ${ }^{3}$ As I am mainly interested in the sorting between Democrats and Republicans, I focus on Democrats and Republicans. Beyond trends between the parties, this study seeks to understand within-party variation. Thus, I analyze how immigration attitudes among Democrats and among Republicans differ by key predictors of immigration attitudes, including: income (by terciles), education (1. less than HS, 2. HS, 3. Some College/AA, 4. BA, 5. Advanced Degree), and geographic region. I also include several variables that are typical predictors of social-political attitudes: sex (male), religion (religious tradition, religiosity, and church attendance), and age (I use a categorical age term: 18-29, 30-39, 40-49, 50-59, 60-69, 70). Finally, I include measures of partisanship (e.g., "Strong Democrat" vs. "Democrat") and political ideology (Liberal, Moderate, Conservative) ${ }^{4}$. See Table 1 of the appendix for weighted descriptive statistics.

\footnotetext{
${ }^{2}$ Figure 11 in the appendix includes over-time trends by party with the five-outcome immigration item

${ }^{3}$ See Appendix D for over-time trends including a five-category party identification variable. For the within-party analyses, a reduced partisan variable is used because I treat partisan strength as a within-party cleavage (e.g., strong vs. weak Democrats.)

${ }^{4}$ Because of small cell sizes, I use a three-way ideology variable that has been collapsed from the standard seven-point ideology scale: "Very liberal" to "Very conservative."
} 


\section{Analytic strategy}

In order to understand the parties' respective strategies toward immigration, the analysis aims to (1) demonstrate how immigration attitudes have changed over time in the aggregate, (2) measure how these attitudes have been patterned by party (between-party variation), and (3) measure within-party variation in this attitudes.

First, to measure how immigration attitudes have trended over time, I run a simple ordinal logistic regression (OLR), regressing immigration attitudes on year. Second, to measure between-party variation, I regress immigration attitudes on a year Xparty interaction; a test of the differences between parties over time provides a direct test of sorting. Next, I turn to within-party variation. I measure within-party variation on immigration in two ways. The first approach provides an overall measure of variation in parties over time; the second provides a closer look at sites of disagreement within each party (i.e., sources of variation) by measuring cleavages.

To measure overall variability within the parties, I fit a variance function regression with a two-step maximum likelihood (ML) approach, predicting variation in immigration attitudes (Western and Bloome 2009). A variance function regression writes the mean, $\hat{y}_{i}$, and the variance, $\sigma_{i}$, both as a function of covariates:

$$
\begin{gathered}
\hat{y}_{i}=x_{i}^{\prime} \beta \\
\log \sigma_{i}^{2}=z_{i}^{\prime} \lambda
\end{gathered}
$$

where $x_{i}$ is a $K \times 1$ vector of covariates for the mean, and $z_{i}$ is a $J \times 1$ vector of covariates for the variance. For the purposes of the variance function regression, $y$, the immigration attitude item, is treated as continuous. ${ }^{5}$ Both $x_{i}$ and $z_{i}$ include party identification, year, and a partyXyear interaction term. Because I am interested in changes in the overall variation among Democrats and Republicans, I do not include further controls, as I am not interested in the adjusted over-time within-party variation. A variance coefficient, $\lambda_{j}$, can be interpreted as the difference in the log variance associated with a one-unit change in $z_{j}$, adjusted for other covariates in $z_{i}$. Here, the key coefficient of interest, partyXyear, measures the difference in variation between Democrats and Republicans on immigration attitudes over time.

Next, to explain what is driving ${ }^{6}$ the within-party variation demonstrated by the variance function regression, I identify cleavages among Democrats and Republicans on immigration attitudes by employing the kappa index. Kappa $(\kappa)$ measures the average distance from the mean among groups for some outcome of interest (Manza and Brooks 1999; Brooks and Manza 1997; Hout et al. 1995). While this measure has been used extensively to measure social cleavages in national electoral outcomes (e.g., the change in the U.S. religious and class cleavages in national elections over time (Manza and Brooks 1999; Brooks and Manza 1997), it can also effectively measure within-party cleavages for a given attitudinal outcome. Past

\footnotetext{
${ }^{5}$ Unfortunately, to my knowledge, a nonlinear version of variance function regression has not yet been developed. As such, I am forced to model the ordinal outcome variable with a linear model. Doing so has potentially important consequences as this model may violate OLS assumptions about linearity. However, the present approach is the best available option.

${ }^{6}$ When I use the term "driving", I am referring the important variables that explain within-party variation when within-party trends are decomposed. "Driving" is not meant to imply causality.
} 
studies utilizing kappa have derived the index from logit coefficients, meaning kappa has been interpreted as the average difference in the log-odds for a given socio-demographic variable with a given outcome; these kappas, then, can be compared over time to measure changes in the average difference among groups (i.e., changes in the cleavage) (Hout et al. 1995). However given the difficulties in comparing logit coefficients across groups and models, as well as the difficulty in interpreting log-odds substantively, I transform the logits into predicted probabilities (Brooks and Manza 1997). Deriving kappa from predicted probabilities is preferred as predictions from nonlinear models do not suffer from the same cross-model comparison issues as logit coefficients; moreover, predicted probabilities measure the outcome in its natural metric, allowing for more meaningful interpretations (Long and Mustillo 2018; Mize 2019; Mize et al. 2019). Thus, kappa measures the standard deviation of the predicted probabilities of each level of an outcome $(j)$ for each level $(k)$ of a given variable (cleavage) in a given year $(t)$. Equation 2 formally defines kappa as:

$$
\kappa_{t}=\sqrt{\frac{\sum_{k=1}^{K}\left(P_{k j t}-\bar{P}_{j t}\right)^{2}}{K}} .
$$

To use an example from Brooks and Manza's 1997 American Sociological Review article on social cleavages and changing political alignments in U.S. Presidential Elections, $\mathrm{K}=$ the number of categories in a given cleavage (e.g., religious sects), $P=$ the probability of vote choice $j(1=$ Democratic candidate, $2=$ Republican candidate $)$, and $t=$ the election year.

Because I am using kappa to measure an ordinal outcome variable, I expand kappa to sum over several outcome variables. I refer to this expanded version of kappa as kappa prime $\left(k a p p a^{\prime}\right)$, and it is formally defined in equation 3 :

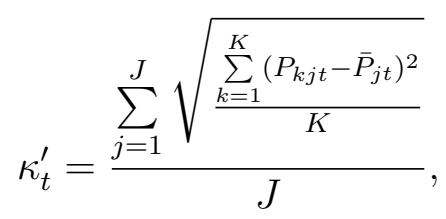

where $J$ is the number of categories for a given outcome variable (e.g., $J=3$ in the case of the immigration attitude variable), $K$ is the number of categories for a given sociodemographic variable (e.g., if the variable of interest is income terciles, $K=3$ as I am using income terciles), $P$ equals the predicted probability for a given category $(k)$ for a given level of the outcome $(j)$, in a given year $(t)$. Simply put, for a given categorical variable in a given year, $\kappa^{\prime}$ calculates the average of the standard deviations of the predicted probabilities for each level of the outcome. I derive $\kappa^{\prime}$ for each socio-demographic variable among Republicans and Democrats for each year; separate models are run for the calculation of each $\kappa^{\prime}$, where in each model I allow the variable of interest to vary by year. For example, to calculate the education cleavage among democrats over time, I 1) fit an OLR, regressing immigration attitudes on an educationXyear interaction, controlling for other variables (including only Democrats); 2) I then obtain the predicted probabilities for each outcome among each education level for each year; 3) finally, the predicted probabilities are then used to calculate the $\kappa^{\prime}$ for education in each year among Democrats. 
$\kappa^{\prime}$ provides an informative description of the dispersion in immigration views among categories of a given variable. However, this measure may give us a distorted understanding of each variable's contribution to the overall variation because $\kappa^{\prime}$ does not take into account the relative sizes of categories within variables. For example, when calculating the religious tradition cleavage, each category (i.e., Catholics, Protestants, Jews, etc.) would be weighted the same, as the average differences among these categories is the measure of interest. But to better assess the direct contribution of the religious tradition cleavage to the overall variation in each party, we may not want to weight each category the same, as the proportions of these categories vary drastically (e.g., In 2016, Jews makeup 2 percent of the religionists in the sample, whereas Protestants make up 48 percent). These differences in relative category sizes could potentially distort our understanding of the religious tradition cleavage as a source of variation among parties if, for instance, Jews have immigration views that are sizably different from the rest of the categories, as they would disproportionately drive up the average difference among categories in the variable. To get an overall sense of the religious tradition cleavage, we would weight Jews equally when calculating $\kappa^{\prime}$, but to get a better measure of the contribution of the religious tradition cleavage to the overall variation within parties, we would need to weight the contribution of each religious tradition by their relative sizes within the parties. As such, I derive a weighted measure, weighted $\kappa^{\prime}$, that weights the contribution of categories by their relative size in each year. Whereas $\kappa^{\prime}$ weighs each category the same, weighted $\kappa^{\prime}$ essentially weighs each individual the same. Equation 4 formally defines weighted $\kappa^{\prime}$ :

$$
\text { Weighted } \kappa_{t}^{\prime}=\frac{\sum_{j=1}^{J} \sqrt{\sum_{k=1}^{K} \omega_{k t}\left(P_{k j t}-\bar{P}^{*}{ }_{j t}\right)^{2}}}{J}
$$

Equation 4 differs from Equation 3 in two ways. First, a weight variable, $\omega$, is added to adjust for the relative contribution of each category, $k$, in time $t$. Because the weights sum to one, the denominator under the square root is dropped, as the weights imply a divisor of $K{ }^{7}$ This weight is equal to the proportion of respondents in category, $k$, at time $t$. Second, a weighted mean, $\bar{P}^{*}$, is used to account for the distributional effects on the mean probability of outcome $j$, for a given variable, $K$, in year $t$.

Because weighted $\kappa^{\prime}$ is simply adjusted by the year-specific distributions of variables, we can fix the weights to represent distributions in any year. Doing so creates a sort of counter factual scenario in which one can assess the impact of population changes within a party (e.g., are attitudes changing or has the makeup of parties simply changed?). I test for the possibility of distributional effects by calculating weighted $\kappa^{\prime}$ s fixing weights at 1992 levels.

Weighted $\kappa^{\prime}$ s provide a concise and interpretable measure of cleavages within parties. These cleavages represent potential sites of exploitation by opposing parties in elections. To make more specific predictions, though, we can easily decompose the weighted $\kappa^{\prime}$ s into their individual respective categorical trends. For example, if there is a growing religious cleavage among Democrats on immigration, are anti-immigration driving this trend? Decomposed weighted $\kappa^{\prime} \mathrm{s}$, then, provide a closer look at the drivers of within-party variation and allow

\footnotetext{
${ }^{7}$ For instance, if both the weights and the $K$ divisor are included, one would essentially be dividing by $K$ twice.
} 
for predictions about future potential realignments (Hillygus and Shields 2009; Manza and Brooks 1999); to expand on the Evangelical example, if there is a sizable proportion of Evangelical Democrats who are anti-immigration and immigration is made a salient issue in the election, these voters may be potential defectors from the Democratic party and, possibly, future party switchers. In short, decomposed weighted $\kappa^{\prime} \mathrm{s}$ allow for predictions about how issues might play out in future elections. I conclude the analysis by discussing trends in these decomposed weighted $\kappa^{\prime}$ s.

\section{Results}

\section{Overall trend in immigration attitudes}

To first understand trends in immigration attitudes at the aggregate level, I present overtime trends for the outcome variable with the full sample. Figure 2 shows the mean probabilities for each outcome category over time, with an accompanying 95\%-confidence interval. In short, this figure demonstrates that there has been an overall decrease in antiimmigration sentiment, accompanied by a slight increase in more favorable immigration sentiment since the early 1990s. This finding confirms Hypothesis 1b, that immigration attitudes have remained relatively stable in the aggregate rather than demonstrating increased anti-immigration sentiment.

Figure 2: Immigration attitudes over time (overall)

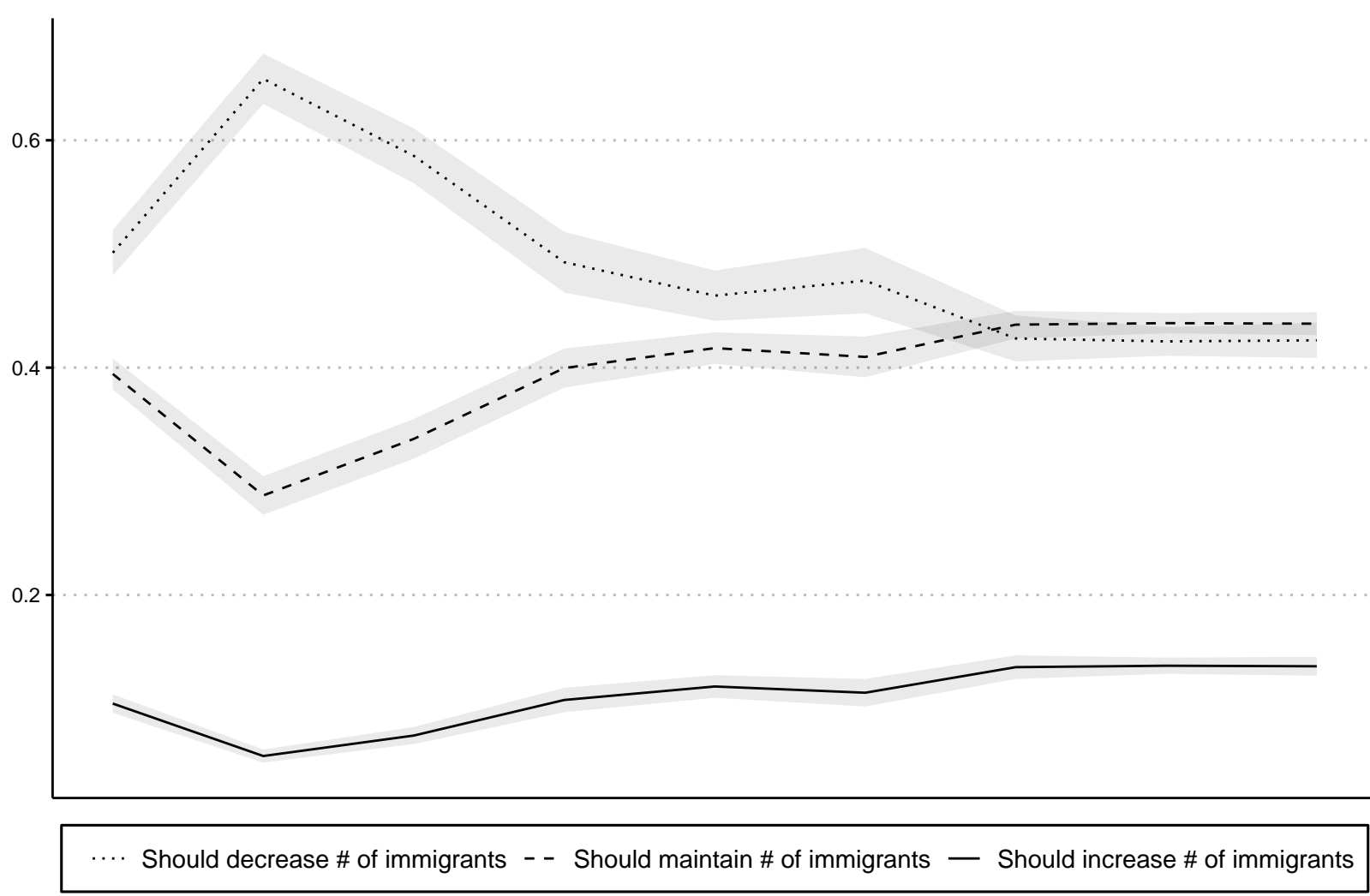


We see a spike in anti-immigration sentiment in 1994, when nearly $70 \%$ of Americans thought the number of immigrants should be decreased, followed by a precipitous decline over the remainder of the 1990s. The overall anti-immigration sentiment continues to decline until we see a leveling out following 2008. Without data points for the years preceding 1992, it is hard to know if the patterns in 1994 is in fact a sudden "spike," but one possible explanation for this trend is that it is a backlash to the 1990 Immigration Act signed by the Bush administration, which increased the amount of legal immigration. While we would expect to see reaction to this bill show up in 1992, it may be that the backlash didn't set in until some years later when politicians began running campaigns in opposition to the bill, subsequently resulting in the Illegal Immigration Reform and Immigrant Responsibility Act of 1996 signed into law by Clinton. The saliency of illegal immigration during this period, perhaps, fed into more positive sentiment toward legal immigration in the years following that reform.

Noticeably, there is another up-tick in anti-immigration sentiment from 2000 to 2004, which has been interpreted as a surge in restrictive nationalism following the 2001 September 11th attacks (Bonikowski and DiMaggio 2016). On average, though, this trend reverses in 2008, where we see about equal proportions (40 percent each) of Americans who think the number of immigrants should either be maintained or decreased, these proportions hold steady until 2016.

Again, looking at the aggregate trends suggests that Americans have on average become less anti-immigrant since the early 1990s, and there has even been a slight up-tick in the number of Americans who think the number of immigrants should be increased. When only considering these aggregate trends, the current saliency of immigration and prominent anti-immigration rhetoric seems surprising. However, looking at aggregate trends in immigration attitudes obfuscates important and documented underlying variation-namely, partisan-sorting (Bonikowski et al. 2019; Sides et al. 2018). To understand the current saliency of immigration in the U.S. political arena, and the parties' respective strategies toward this issue, I now turn to trends at the between-party level.

\section{Party polarization}

Figure 3 shows trends over time in immigration attitudes by party. Compared to Democrats, Republicans appear to show slightly more anti-immigration sentiment throughout the 1990s and into the early 2000s, but the difference is small. In fact, both parties show remarkably similar patterns up until 2008. Following 2008, we see marked party polarization on immigration attitudes. Among Republicans, there is a steep rise in anti-immigrant sentiment from 2008 to 2012, and this rise continues into 2016, where it reaches its highest value since 1994. Over this same time, there is a decreased probability of saying the number of immigrants should be increased or maintained among Republicans. 
Figure 3: Immigration attitudes over time (by party)

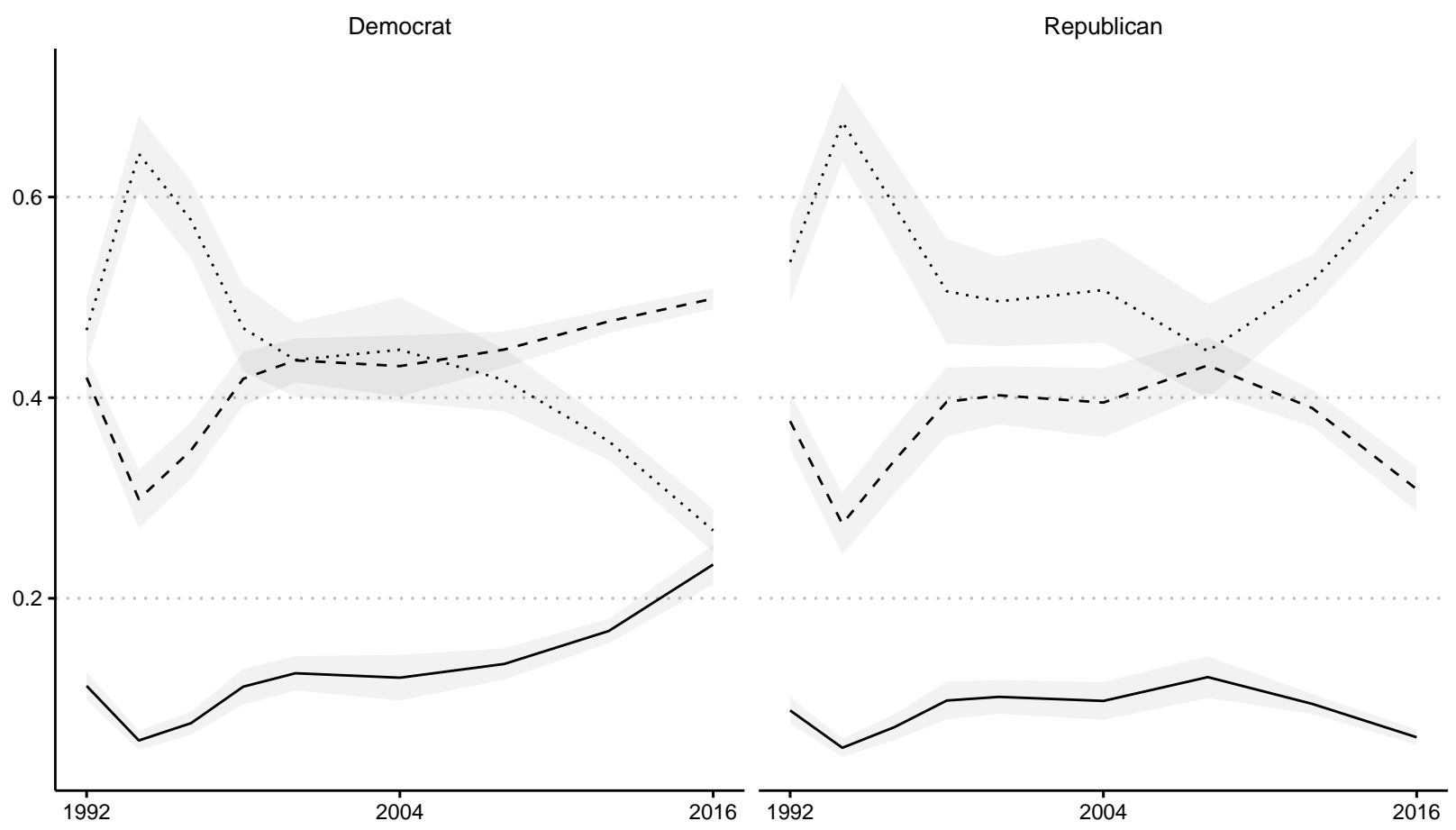

... Should decrease \# of immigrants - - Should maintain \# of immigrants — Should increase \# of immigrants

Figure 4: Over-time ADC on anti-immigration attitudes

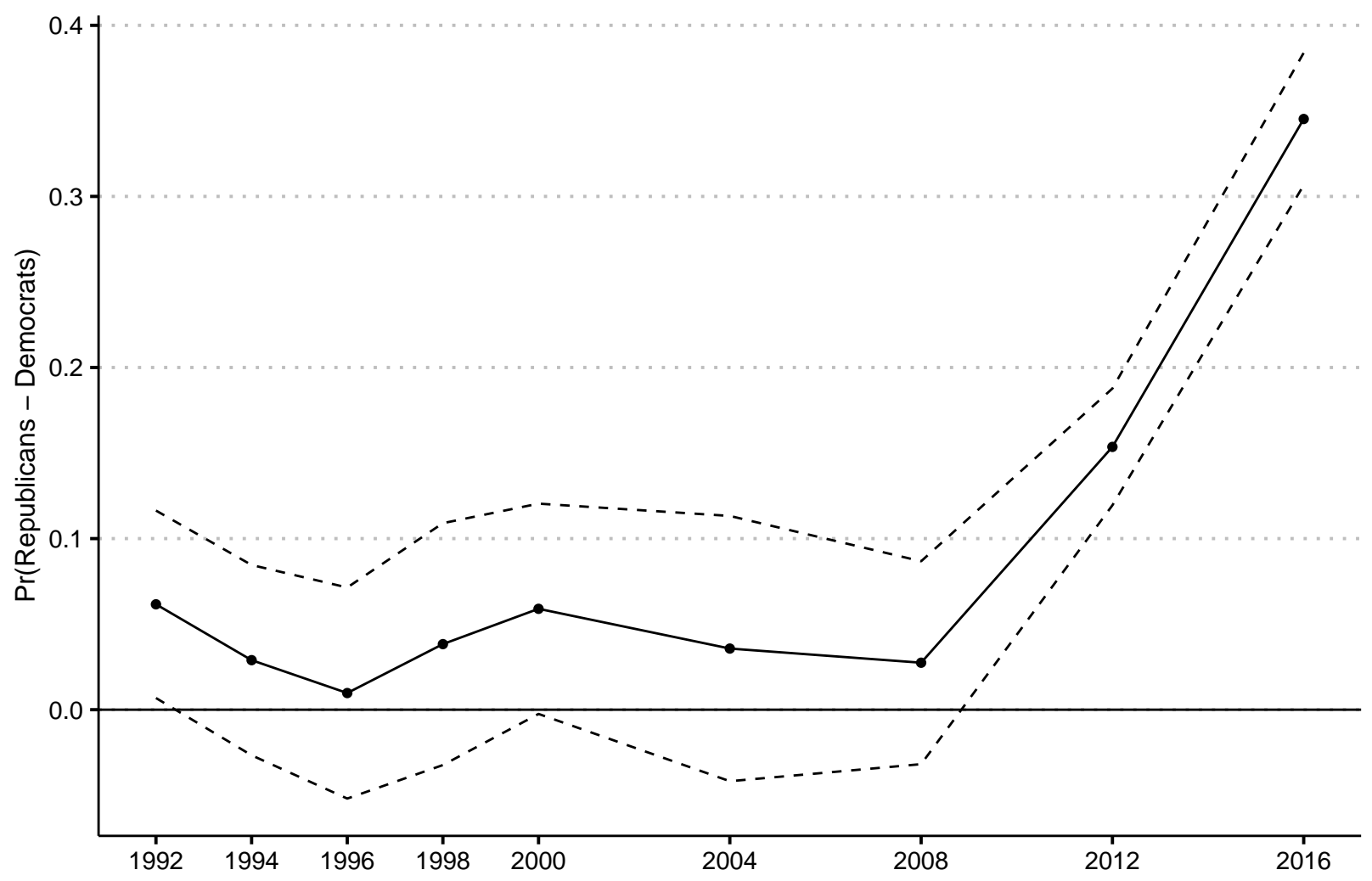


In comparison, we see nearly mirror effects among Democrats, with decreasing antiimmigration sentiment and accompanying increases in the probabilities for "increasing the number of immigrants" and "maintaining the number of immigrants." In line with recent work on this issue (Sides et al. 2018), Figure 3 demonstrates that there has been clear party polarization on immigration attitudes since 2008. This trend is being driven by the steep increase in negative immigrant sentiment among Republicans following 2008 and the continuation of a more pro-immigrant trend among Democrats since 2004. Figure 4 models this polarization more formally, plotting the average discrete change (ADC) ${ }^{8}$ between Republicans and Democrats over time on the first outcome: "Decrease the number of immigrants." The dotted lines around the trend line mark the $95 \%$ confidence interval; points in which the lower bound crosses the solid horizontal line indicate a non-significant difference between the parties in that year. From this figure, we clearly see the recent polarization on anti-immigration attitudes: There is a non-significant difference between the parties in each year before 2012, except in 1992, when the party difference is small, but just meets significance at the $95 \%$ level. ${ }^{9}$ These results confirm Hypothesis 2 and past work that demonstrated the increased partisan sorting of immigration attitudes.

Given the symmetrical polarization of Democrats and Republicans on immigration in recent years, as well as the issue's continued saliency, we would expect both parties to tout immigration as a core issue, providing clear ideological alternatives in the political arena (De Sio and Weber 2014; Abramowitz 2013). But that did not happen. While Republicans made immigration a central theme to their campaigns, Democrats largely shied away from the issue. And thus studying attitudes at the aggregate and between-party levels cannot fully explain party strategies on immigration, a hot-button issue that has become firmly sorted by party: Why have Democrats not touted immigration as Republicans have? Theories on party strategy and issues suggests that we must analyze within-party trends to answer this question (De Sio and Weber 2014; Hillygus and Shields 2009), and it is these results to which I now turn.

\section{Within-party variation on immigration attitudes}

\section{Overall heterogeneity on immigration attitudes}

To first get a sense of the overall variation within the parties on immigration attitudes, Figure 5 shows the predicted logged variance for Democrats and Republicans over time; these predictions come from a variance function regression, plotting the year Xparty interaction. ${ }^{10}$ As with the trends in means over time, the largest distinction between the parties emerges in recent years, with Republicans becoming sharply more consistent in their immigration views and Democrats becoming steadily more variable. Overall, the results from the variance function indicate that, while Democrats have become steadily more pro-immigration since

\footnotetext{
${ }^{8}$ For a categorical variable, an average discrete change measures the difference in probabilities between a given category and the baseline category. In this instance, it is simply a measure of the difference in predicted probabilities between Republicans and Democrats for having anti-immigration views across each year.

${ }^{9}$ See Appendix B [Table 2] for tabular display of regression results.

${ }^{10}$ Trend lines have been smoothed to better capture over-time trends and de-emphasize year-to-year fluctuation
} 
Figure 5: Predicted within-party variation over time. Differences are statistically different at the $95 \%$ level in 1992, 2004, 2012, and 2016.

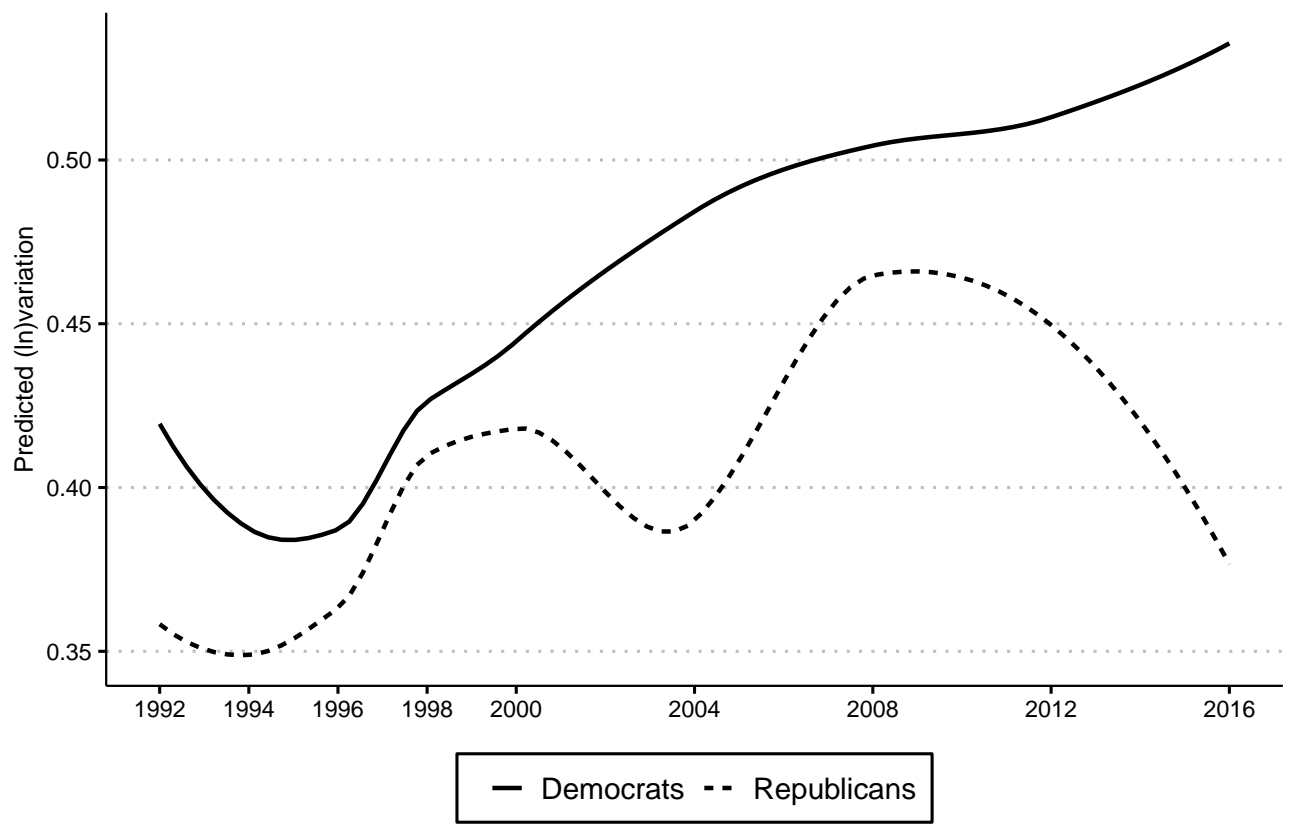

2008, they have also become more variable on the issue. Comparatively, Republicans have become sharply more anti-immigration and consistently so. ${ }^{11}$ This finding is in clear support of Hypothesis 3.

\section{Explaining within-party variation: Within-party cleavages}

Figure 5 demonstrated the over-time trends of within-party variation. But what is driving the within-party variation among Republicans and Democrats? That is, what kinds of Democrats are disagreeing on immigration, and what kinds of Republicans used to disagree but now agree on immigration? These within-party cleavages represent both the sources of conflict within parties and opportunities to implement "wedge politics" for the opposing party (Hillygus and Shields 2009). To measure trends in within-party cleavages and contributions to overall within-party variation, I calculate weighted $\kappa^{\prime}$ indices for each socio-demographic variable among Democrats and Republicans over time. Figure 6 plots smoothed trend lines of the weighted $\kappa^{\prime}$ scores; larger values indicate a larger cleavage in that year-larger dispersement. The solid trend lines indicate the weighted $\kappa^{\prime}$ scores derived from baseline models fit without controls, and the dashed lines indicate scores derived from models including controls. Plotting both the full and baseline models together provides a convenient way of understanding which categories' trends are being affected by the inclusion of other variables in the model. To clarify, when I refer to a "socio-demographic variable" or simply a "variable", I am referring to patterns by sub-party variables (e.g., Education among Democrats); when I refer to a "group", I am referencing categories within sub-party variables

\footnotetext{
${ }^{11}$ See Appendix C for robustness checks on the variance function analysis. See Table 3 of Appendix B for variance function results in tabular form.
} 
(e.g., BA vs. <BA among Democrats). Graphical displays of weighted $\kappa^{\prime}$ indices over time give us a wealth of information; first, we can easily identify which variables contain large cleavages versus small between-group variability both overall and in a given year. Second, we can see how these cleavages have developed over time - it is equally important to identify variables that have had growing cleavages and variables that have had their between-group differences shrink. For example, if a variable has relatively high between-group variability in 2008 but this variability shrinks drastically in subsequent years, this is a clear demonstration of party alignment among this sub-party variable ${ }^{12}$. Alternatively, if a variable has relatively low between-group variation in the early 2000s, but then increases its variability in recent years, this suggests that this variable is an important site of disagreement within the party. Third, as I am using the weighted $\kappa^{\prime}$ measure, these trends tell us which cleavages are contributing most strongly to the overall within-party variation in a given year.

I could also, of course, display trends for the non-weighted $\kappa^{\prime}$ measure, which would show over-time trends in cleavages, regardless of group sizes. The choice to use either the weighted $\kappa^{\prime}$ or the unweighted $\kappa^{\prime}$ is a theoretical one. Again, because weighted $\kappa^{\prime}$ is a more direct measure of contribution to variation, I have chosen to focus on its trends here. The results between the two measures are largely the same, indicating that group sizes are not drastically altering the substantive conclusions. ${ }^{13}$ See Appendix D for trends using unweighted kappas.

\footnotetext{
${ }^{12}$ Such a trend could also be driven by over-time partisan sorting in terms of people selecting into parties with which they agree. As I do not have longitudinal data, I cannot control for this selection effect. Regardless of potential selection, though, shrinking cleavages are suggested of alignment on immigration attitudes.

${ }^{13}$ The most drastic changes occur when there are especially small categories, as is the case with religion, where the proportion of Jews among religionists is very small.
} 
Figure 6: Smoothed Weighted $\kappa^{\prime}$ indices trends for Democrats and Republicans

\section{Democrats}

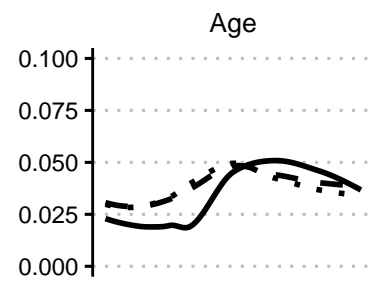

Political Ideology
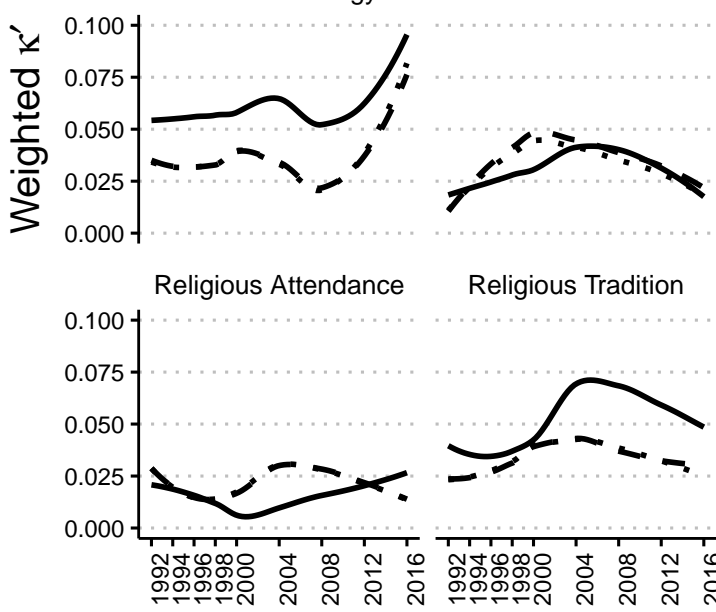

Religious Tradition
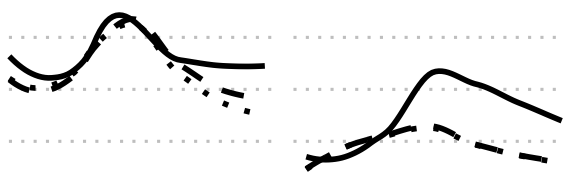

Region
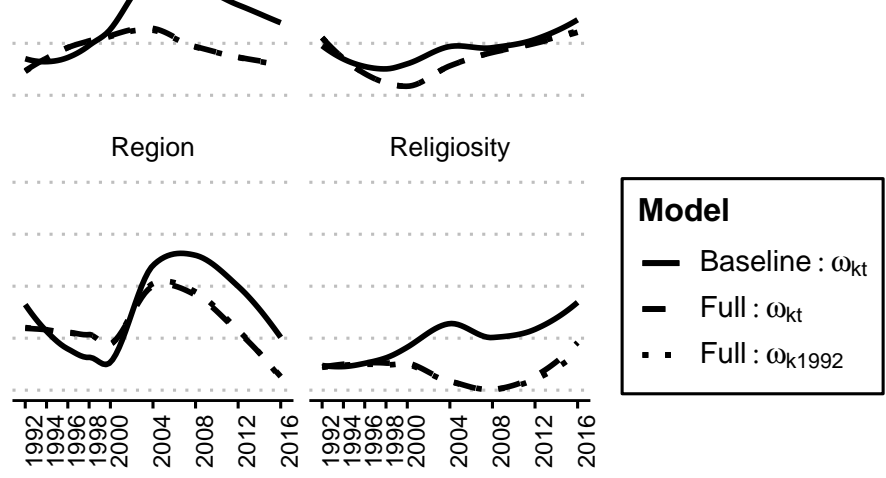

Religiosity

Model

- Baseline: $\omega_{\mathrm{kt}}$

- Full : $\omega_{\mathrm{kt}}$

- Full : $\omega_{\mathrm{k} 1992}$
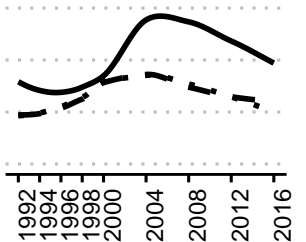

\section{Republicans}

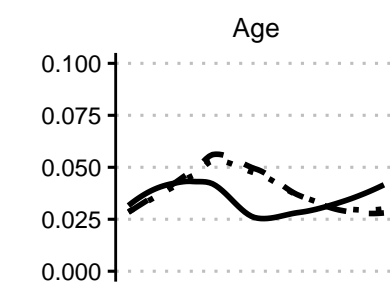

Political Ideology
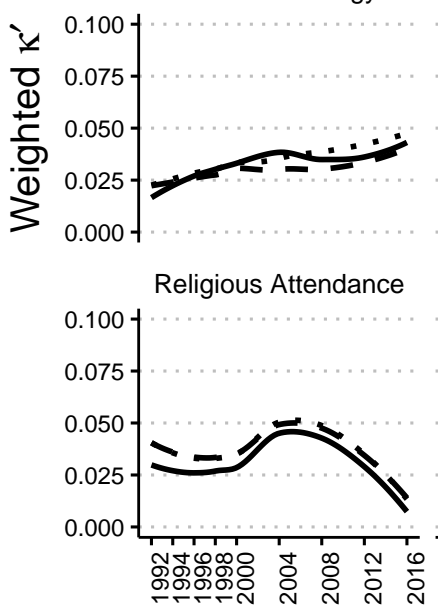

Education

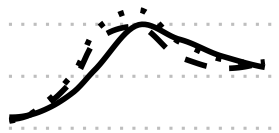

Race

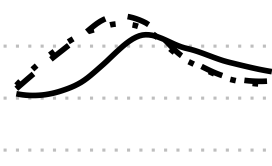

Religious Tradition

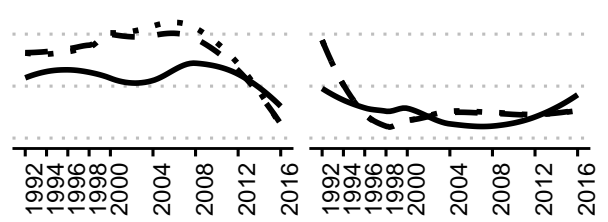

Model

- Baseline: $\omega_{\mathrm{kt}}$

- Full: $\omega_{\mathrm{kt}}$

- Full : $\omega_{\mathrm{k} 1992}$ 
Among Democrats, we see clear differences between socio-demographic variables in terms of their weighted $\kappa^{\prime}$ index levels and the over-time trends of these indices. First, political ideology appears to be a clear driver of variation among Democrats in recent years. Following 2008 , the weighted $\kappa^{\prime}$ rises sharply and is the only variable for which there has been a clear increase since 2008, and this holds true in both the baseline and full models, suggesting that this trend is not due to growing divides among correlates of political ideology.

Partisanship and religiosity have also increased, but the trends are less dramatic. Although the cleavage has shrunk in recent years, education stands out as a significant source of variation. Further, there is a noticeable spike in 2004, where the weighted $\kappa^{\prime}$ reaches the highest level among any variable in any year apart from ideology in 2016, but then there is a subsequent decline in the cleavage in the following waves, where it reaches levels similar to the 1990s; moreover, the small difference between the baseline and full models for education is notable and is suggestive of the variable's importance relative to other variables in the model. The large education cleavage in 2004 is indicative of varied responses to the September 11th attacks along educational lines (Bonikowski et al. 2019; Bonikowski and DiMaggio 2016). Religious tradition demonstrates a similar magnitude and trend to education, with a spike in 2004 and steady decline in subsequent years. Race and geographic region were both fairly large cleavages, but both variables have sharply declined in their between-group variability since 2004, and both have index scores of nearly zero by 2016. Gender, religious attendance, and religiosity all show consistently low cleavage levels across waves. While the baseline models for income suggest fairly high and consistent cleavage levels, these differences among income groups are attenuated in the full models, especially by education. ${ }^{14}$ Finally, distinct from other variables, age showed very little variation throughout the 1990s, but a more distinct age cleavage emerged in 2004. Since then, the differences among age groups have stayed level or have slightly declined.

The patterns are noticeably different among Republicans compared to Democrats. The increased consistency among Republicans in recent years appears to be driven by declines in the race, regional, and religious attendance cleavages. The age cleavage has also steadily declined. Notably, ideology and partisanship are contributing to the within-party variation differently compared to Democrats; while there has been an increase in the ideology and partisan cleavages in recent years, these increases are not as dramatic compared to Democrats. The education cleavage again stands out among Republicans, with a similar highpoint in 2004, but the subsequent decline is not as sharp as with Democrats. Several variables among Republicans show steady and relatively low cleavage levels over time. Gender, income, religiosity, age, and religious tradition all demonstrate fairly steady and small cleavage levels over time.

In sum, Figure 6 gives us insight into the sources of variation among Democrats and Republicans over time on immigration attitudes. Among Democrats, a clear ideological cleavage has emerged in recent years, as well as a steadily increasing partisan cleavage, explaining the increased variation among Democrats. For Republicans, the increased consistency in recent years on immigration can be best attributed to a sharp decrease in the regional, race, and religious attendance cleavages, which more than offsets more modest increases in ideological

\footnotetext{
${ }^{14}$ Step-wise regressions demonstrate that the inclusion of education dramatically attenuates the effect of income group on immigration attitudes.
} 
and partisan cleavages.

While Weighted $\kappa^{\prime}$ takes into account groups sizes in a given year, this does not account for the potential effect of over-time compositional shits that could be influencing trends. Given the well-documented compositional shifts among Republicans and Democrats over the last several decades, the results could be driven by changes in the make-up of parties rather than attitudinal changes. To test this, I calculated Weighted $\kappa^{\prime}$ indices derived from full models, fixing group sizes to their 1992 levels $\left(\omega_{k 1992}\right)$; trends for Weighted $\kappa^{\prime}$ indices fixed at 1992 group sizes are plotted with the dotted lines. These trends display a counterfactual scenario in which the party compositions have remained the same since 1992, thus capturing the possible effects of composition shifts on our understanding of cleavage trends. The influence of compositional shifts can be ascertained, then, by looking at the gap between the dotted and dashed (full models with year-to-year composition weights) in a given year. For instance, if the age cleavage estimate among Democrats is much lower in 2016 for the dotted line compared to the dashed line, this would suggest that compositional changes since 1992 have contributed to a larger age cleavage in 2016 then there would have been if the age composition of Democrats had not shifted since 1992.

Overall, the trends do not appear to be affected by over-time compositional shifts, with slight year-to-year deviations for some cleavages. One notable, but small, compositional effect exists for the Republican ideological cleavage. The divergence between trend lines indicates the ideological cleavage among Republicans has been suppressed by compositional shifts over time; the growing share of "conservative" Republicans over the last several decades is well documented, and this shift appears to have suppress what would otherwise be a larger ideological cleavage on immigration attitudes among Republicans. Though, again, this compositional effect is small. (See Figure 9 in the appendix for over-time composition trends among Democrats and Republicans.)

To recap, the overall increase in variation among Democrats is largely being driven by increasing ideological and partisan cleavages; that is, Democrats are increasingly disagreeing on immigration along ideological and partisanship lines; for Republicans, their increasing homogeneity on immigration views is being driven by collapsing religious (measured as church attendance), regional, and racial cleavages: while Republicans used to demonstrate considerable disagreement on immigration along religious, regional, and racial lines, these differences have dissipated, and the party has become relatively uniform on this issue.

The results suggest that Democrats have not made immigration a flashpoint issue for the party because doing so risked disaffecting large segments of the party. Republicans, on the other hand, brought immigration to the forefront in the political arena because this strategy posed little risk of losing party members and had the potential to wedge a divided Democratic party. But, how are these within-party dynamics going to potentially play out in future elections, and how did we get here? That is, what kinds of Democrats are trending apart from the rest of the party on immigration and provide an opportunity for Republicans to gain voters? To shed light on these questions, I now turn to decomposed Weighted $\kappa^{\prime}$ s.

\section{Group trends: decomposing within-party cleavages}

Figures 7 and 8 trend plots for each group of Democrats and Republicans, respectively; that is, these figures plot the predicted probabilities of Socio-demograhpicvariableXyear 
interactions, estimated from full models with controls. For each variable, there is a separate panel for each outcome of the immigration item: "Decrease the number of immigrants", "Maintain the number of immigrants", "Increase the number of immigrants." 15

Figure 7 plots group trends among Democrats. Again, Figure 6 demonstrated that the steadily increasing variation among Democrats is largely a result of growing ideological and partisan cleavages within the party. Here we see that the growing ideological cleavage is a function of liberal Democrats becoming markedly more pro-immigration since 2008, evident in both their decrease in anti-immigration views and increase in pro-immigration views; meanwhile, moderate Democrats have had stable attitudinal trends over this same period of time, and conservative Democrats have actually become more anti-immigration. Thus, we see here that since 2008, Democrats themselves have become polarized along ideological lines. Similarly, there has been growing gap between "Strong Democrats" and "Democrats", with those with strong partisanship being more pro-immigration since 2004.

While not as important as the ideological and partisanship divides, there are notable patterns among other variables, as well. The education cleavage among Democrats is a result of a clear diploma divide: there is a sizable and steady gap among Democrats with a $\mathrm{BA}$ and Democrats without a BA in terms of the probability of holding anti-immigration and pro-immigration views. ${ }^{16}$ While both BA and non-BA holders have become more proimmigrant in recent years, those Democrats with a BA have consistently held notably more pro-immigrant views. While the age cleavage has not grown in recent years, there is marked and growing difference between young Democrats (18-29) and everyone else, who have become consistently more pro-immigration over time. This suggests a future Democratic party that is increasingly pro-immigration and, potentially, increasingly divided on immigration if older Democrats do not become more pro-immigration.

\footnotetext{
${ }^{15}$ Note that these trends represent decomposed $\kappa^{\prime}$ s as opposed to the Weighted $\kappa^{\prime}$ s. That is, these trends in predicted probabilities are not weighted by their relative group sizes.

${ }^{16}$ The models were estimated including a five-category education variable. However, I collapse the categories into a BA/non-BA binary variable for visual display to demonstrate the clear divide.
} 
Figure 7: Democrat immigration attitudes over time. Smoothed trend lines for the predicted probability of outcome.

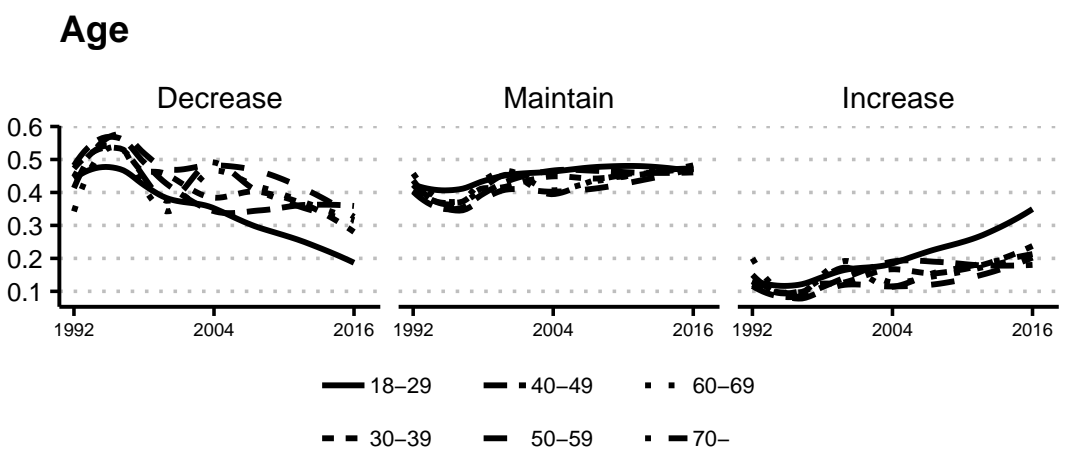

\section{Education}

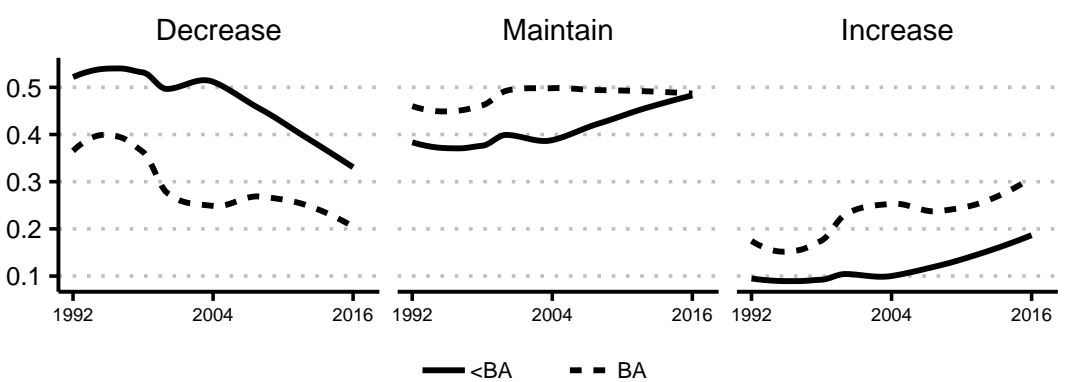

Income

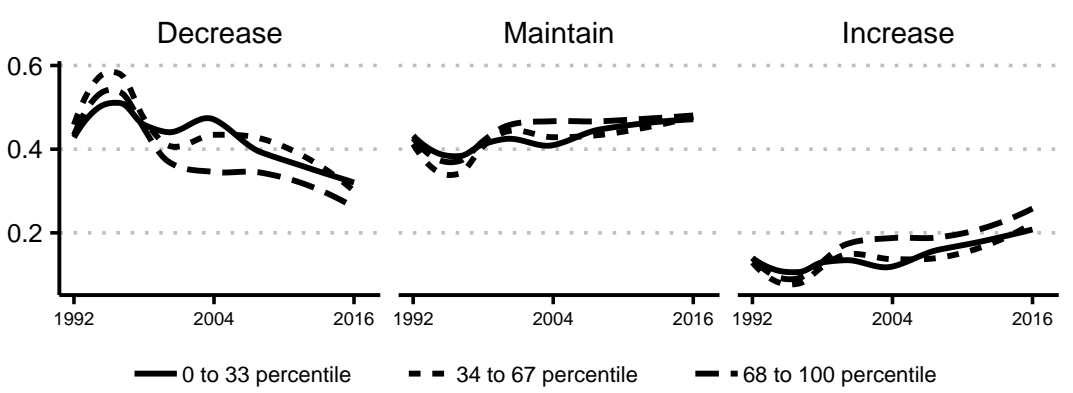

\section{Gender}

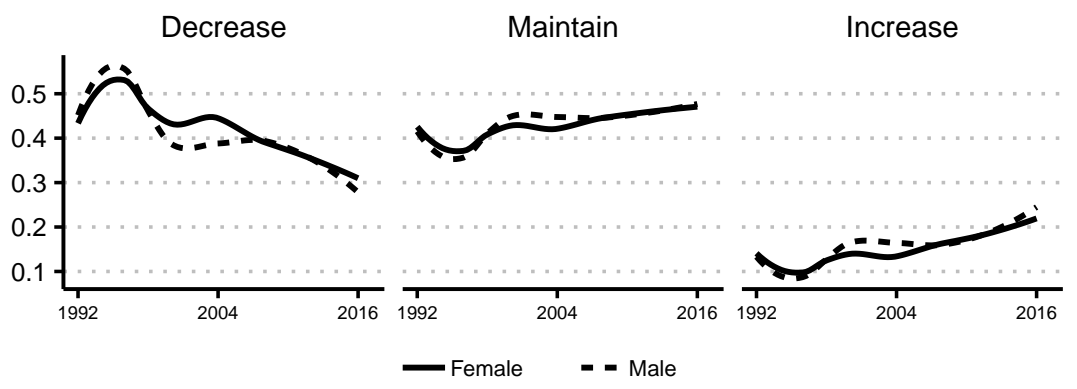

\section{Partisan Identification}

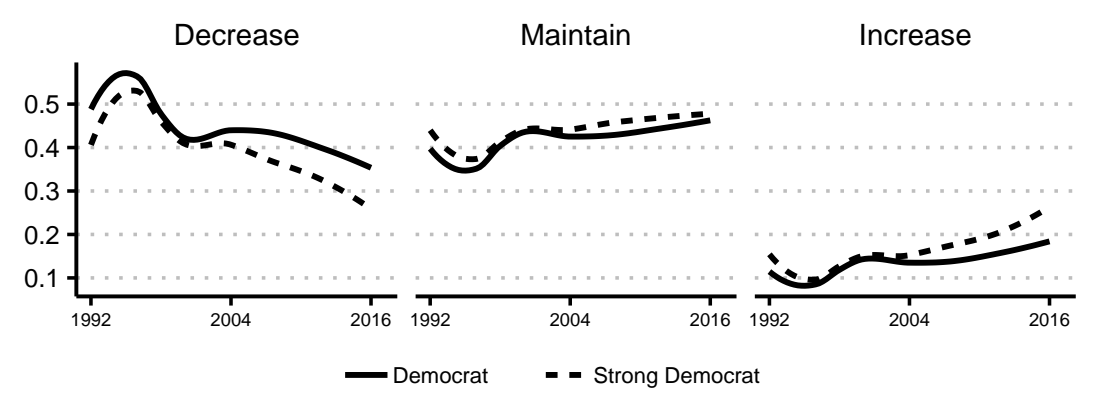

\section{Political Ideology}

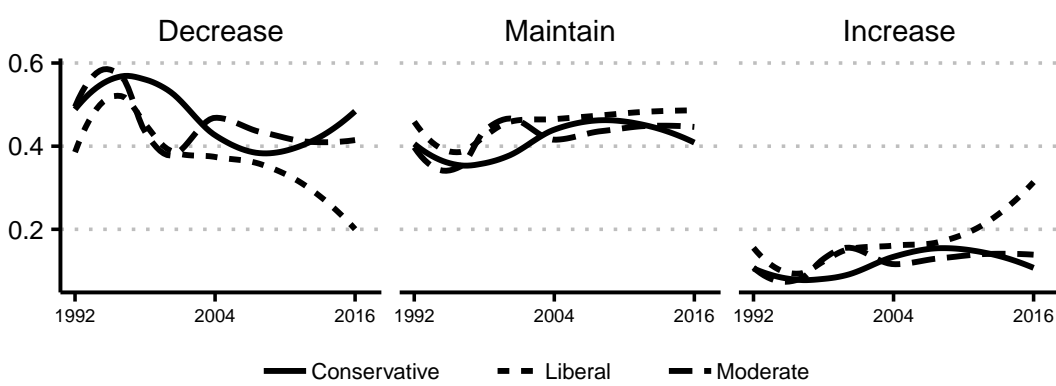

Region

Race

Increase
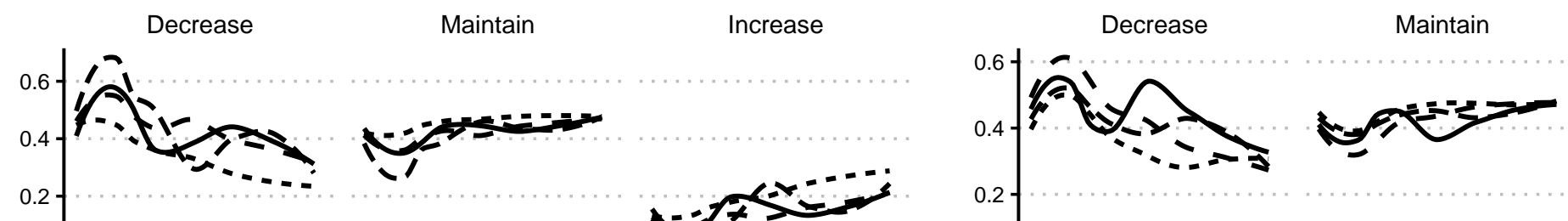

Increase 
Figure 8: Republican immigration attitudes over time. Smoothed trend lines for the predicted probability of outcome.

Age

\section{Education}
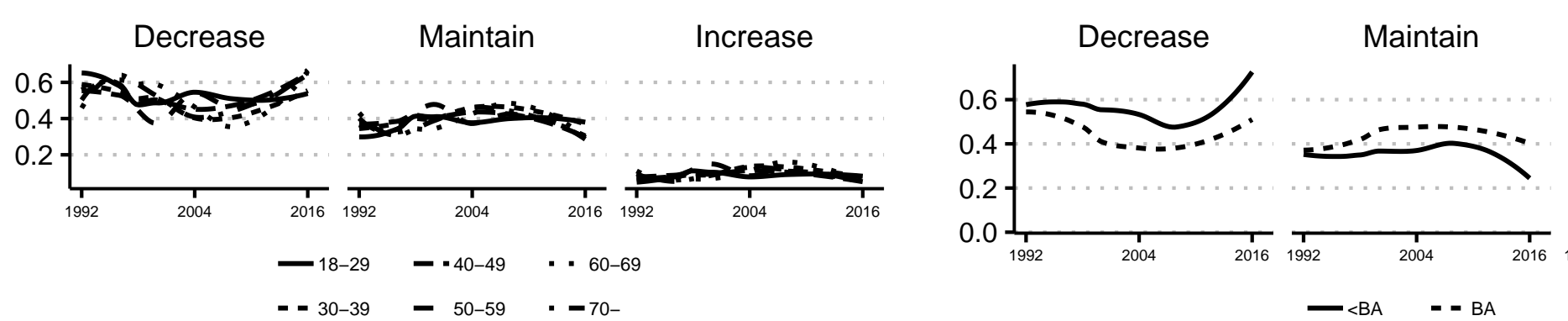

Increase

Income
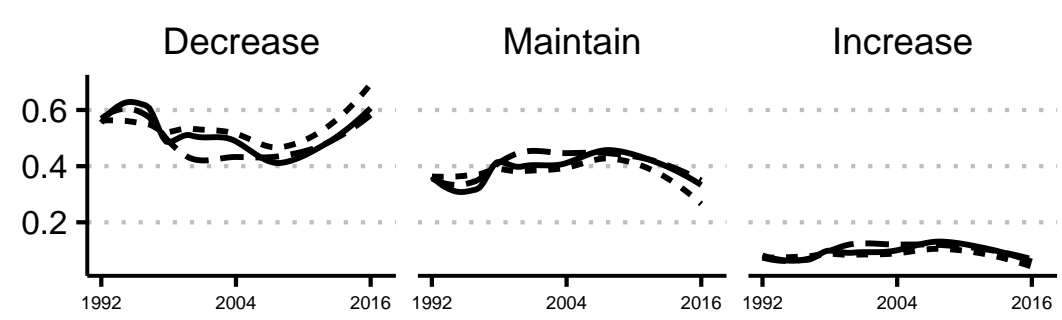

- 0 to 33 percentile

- - 34 to 67 percentile

- 68 to 100 percentile

\section{Partisan Identification}

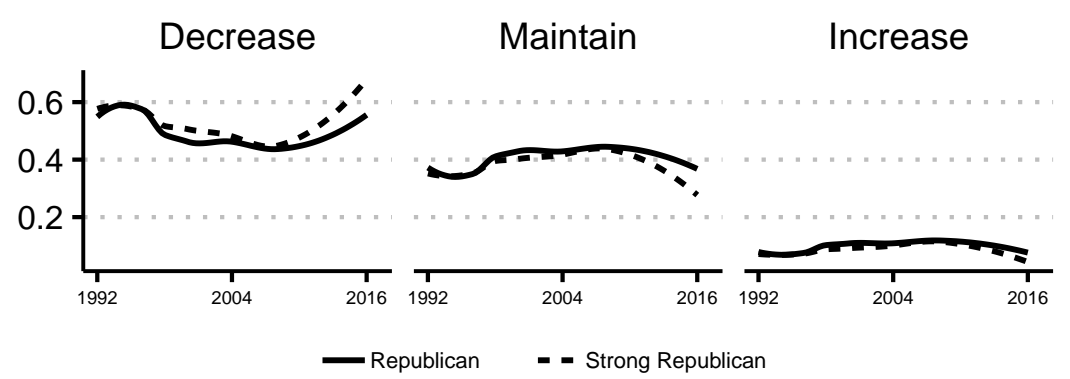

Race

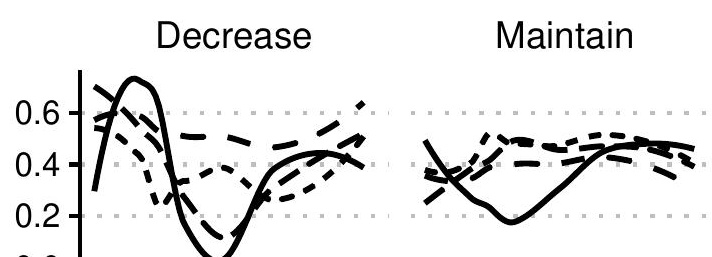

Increase
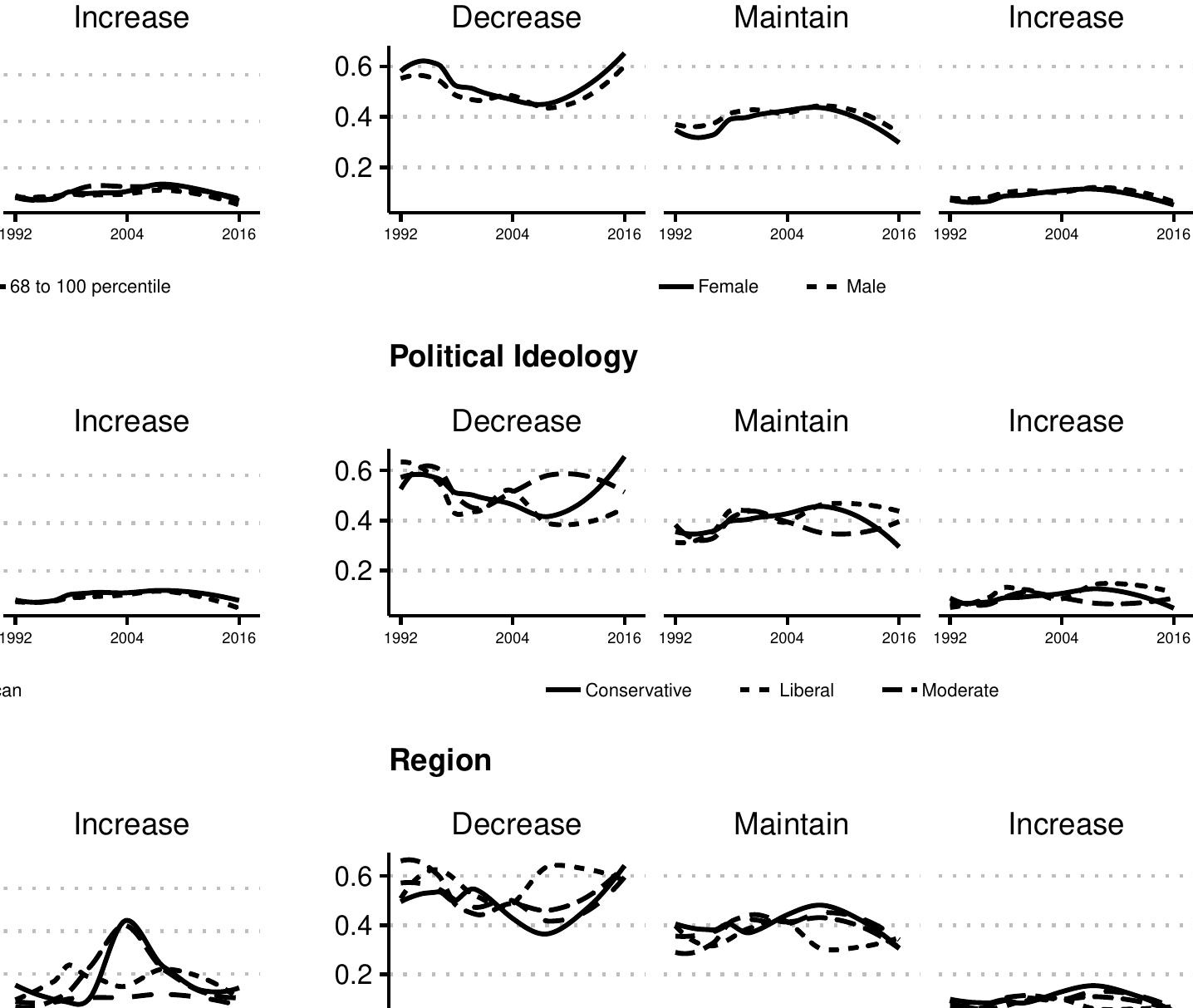

Political Ideology

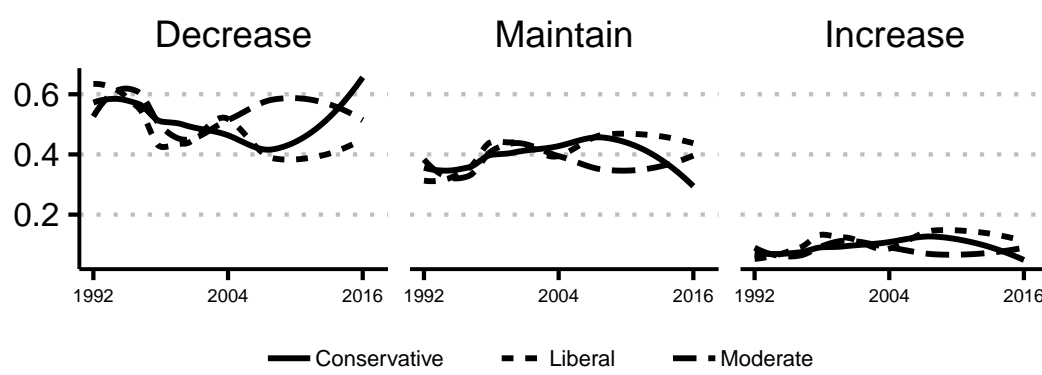

Region

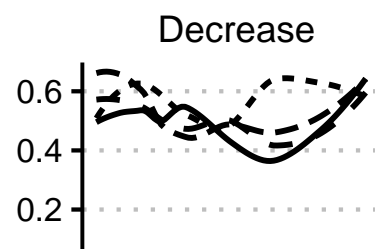

Maintain

Increase

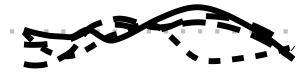


There are notably different patterns for Republicans compared to Democrats (Figure 8). Again, the weighted $\kappa^{\prime}$ indices demonstrated the sharp collapse of several Republican cleavages in recent years, notably region, race, and religion (attendance). The regional cleavage decline appears to be a function of Southern, Midwestern, and Western Republicans becoming more similar to Northeastern Republicans in their anti-immigration views: There was large spike in anti-immigration sentiment among Northeastern Republicans in 2008, and they have maintained this level of anti-immigration; Republicans from other regions have since closed this gap, resulting in the smaller regional cleavage among Republicans. Most striking is the patterns among religious attendance. While a sizable cleavage existed in the mid2000s, this cleavage has collapsed as a result of regular church attenders becoming sharply more anti-immigration in recent years. It appears that while regular church attendance may have served as a buffer from anti-immigration sentiment among Republicans in past years, this function no longer holds, as regular church attenders are just as anti-immigration as occasional church-goers and those who never attend church. This is a striking finding and is consistent with the mobilization of Christian nationalists in recent years (Whitehead and Perry 2020; Bonikowski et al. 2019). The racial cleavage is defined by a steady level of antiimmigration sentiment among white Republicans compared to more varied attitudes among other racial categories. This cleavage has drastically dissipated as a result of a consistent uptick in anti-immigration views among all racial categories since 2004. While the increasingly small share of minority Republicans is well documented, these unifying trends are important, as demonstrated in Figure 4, despite the small number of respondents occupying the non-white categories. Compared to Democrats, the patterns among age groups for Republicans are less clear, but a bit of an age cleavage does appear to develop in 2016, with the two youngest categories having lower levels of anti-immigration attitudes compared to older Republicans. The sharp increase in anti-immigration attitudes among older Republicans following 2008 is particularly eye-catching.

While the ideological cleavage among Republicans is not as pronounced as Democrats, several trends are noteworthy. Interestingly, conservative Republicans, holding all else equal, became the most anti-immigration category in 2016, while moderate Republicans had been the most anti-immigration since 2004. Why have these ideological differences among Republicans not contributed to larger variation among Republicans? As Figure 6 demonstrates, the ideological cleavage among Republicans was suppressed by changing composition, as a large majority of Republicans are made up of self-identified "conservatives" by 2016, which drowns out the differences of moderate and liberal Republicans. This ideological dynamic is different compared to Democrats, as Democrats, while also becoming more liberal, are split more evenly along ideological lines (liberal vs. moderate). So, simply put, the ideological divisions among Democrats are more impactful compared to Republicans because the Republican party has become overwhelmingly conservative in recent years. Like Democrats, the education cleavage does appear to be driven by a diploma divide among Republicans. However, this divide was less pronounced in the early and mid-2000s has become more stark in recent years.

In sum, the growing ideological cleavage among Democrats is best explained by increasingly pro-immigration views among liberals paired with a simultaneous static trend among moderates and an increasingly anti-immigration (small) group of conservative Democrats; similarly, strong Democrats have increasingly pro-immigration views compared to weak 
Democrats. Thus, the steady rise in variation among Democrats on immigration views can best be explained by the growing distinction between liberal, strong Democrats, and the rest of the party. Further, a sizable education gap remains, with lower-educed Democrats demonstrating more anti-immigration sentiment compared to the rest of the party. Republicans, on the other hand, have become sharply more homogeneous on their immigration views, and this can be attributed to a number of factors. Most notably: There is a decreasing distinction between Northeastern Republicans and Republicans in other regions in terms of their antiimmigration views; regular church attenders, who were formally the most pro-immigration Republicans, are now just as anti-immigration as less religious Republicans; and, there has been a dramatic rise in anti-immigration views among conservative Republicans - given that conservative Republicans make up $80 \%$ of the party by 2016, this trend has a major impact on growing uniformity of Republican immigration attitudes.

\section{Discussion and Conclusions}

The literature on mass polarization and partisan sorting has demonstrated a public that is increasingly divided along political lines. In this environment, virtually any salient issue has the potential to become flash points for both parties. Why, then, do parties not emphasize certain hot-button issues symmetrically in an era of high partisanship? This paper has argued that in order to answer this question, social scientists must study attitudes at three levels: (1) the aggregate, (2) between-party, and (3) within-party. Each level provides necessary information for understanding party strategy toward issues and the broader consequences of public opinion for institutional politics. I have applied this analytic strategy to immigration - one of the most salient issues in U.S. and European politics - to understand why Democrats, unlike Republicans, have not touted immigration as a central issue of the party.

The results demonstrate a number of important findings. First, immigration attitudes have been fairly stable at the aggregate level, except for a rise in anti-immigration sentiment in the mid-1990s. Since this short-lived spike, however, the aggregate trends have held steady and, if anything, have become slightly more pro-immigration - a surprising trend given the recent rise in anti-immigration rhetoric and policy proposals (Lamont et al. 2017; Flores 2017, 2018). Second, these trends in the aggregate mask drastic party polarization since 2008, with Republicans becoming sharply more anti-immigration and Democrats becoming more pro-immigration. Third, while the parties have clearly grown apart, the attitudes within the parties have not trended uniformly. While Democrats have become more pro-immigration over the last several years, they have also grown more variable on this issue. In contrast, Republicans have become more anti-immigration and consistently so. In short, the results suggest that Democrats may be reluctant to run on immigration because substantial intraparty disagreement make this strategy too risky; on the other hand, touting immigration poses little risk to a uniform Republican party and provides much upside in their potential to "wedge" a divided Democratic party.

When looking at overall trends on immigration attitudes, the current political climateone of heightened saliency surrounding issues of race and immigration - would seem puzzling (Sides et al. 2018). But once this trend is disaggregated by party, a clear over-time story 
emerges. The similar trends between parties going into 2008 are reflective of the fact that immigration was not highly politically salient during this era (Flores 2018). While the September 11th attacks had severe short-term implications for citizens' national identities (Bonikowski and DiMaggio 2016), Democrats and Republicans had not yet diverged sharply on immigration attitudes. ${ }^{17}$ The years from 2001 to 2008 were marked by an era of "compassionate conservatism, in which ideas of inclusivity were espoused - and this may explain the higher pro-immigration sentiment among Republicans during this period.

This era came to an abrupt ending, however, with the 2008 election, which ushered in a political era marked by the saliency of issues related to race, ethnicity, and immigration (Sides et al. 2018). Following suit, we see a precipitous drop in pro-immigration sentiment among Republicans following 2008. By 2012 Republican party leaders had dropped the "compassionate conservative" brand of the Bush-era Republican party and candidates, including Mitt Romney, ran on platforms that included more restrictive immigration policies.

But following the loss of the 2012 election, in which Latinos and other ethnic minorities played a crucial role in electing Obama to a second term, Republican party leaders decided they needed to turn away from the restrictive immigration policies that had marked their platform in fear of further alienating these voters (Sides et al. 2018; Hajnal and Rivera 2014), and this turn was evident in the 2016 Republican primaries. Mainstream Republican candidates ran on either inclusive immigration policies or didn't emphasize issues related to immigration - this strategy ran in stark contrast to the Trump campaign (Bonikowski et al. 2019; Lamont et al. 2017). Republican leaders were fearful of Trump's anti-immigration rhetoric and its consequences, as this approach was in direct conflict with the image that party elites had attempted to establish over the previous four years. But as several scholars have argued, and is demonstrated here, the demand for anti-immigration rhetoric among Republicans was there (e.g., Bonikowski et al. 2019; Sides et al. 2018): anti-immigration sentiment among Republicans, on average, only grew from 2012 to 2016.

While Republicans have been able to successfully run - and win - on an anti-immigration platform, why have Democrats not been able establish a commensurate pro-immigration platform or campaign strategy, despite a rise in pro-immigration attitudes? One possible explanation for this is that the intra-party dynamics on immigration have varied between Republicans and Democrats. For Republicans, they have not only become more anti-immigration on average, but they have done so consistently; in other words, to be a Republican increasingly means to be anti-immigration. Thus the demand for anti-immigration candidates and policy proposals is there among Republicans, and there is not much risk of backlash from party members, as they are increasingly uniform on this issue. Democrats, however, have become more pro-immigration on average, but this trend is largely being driven by liberals and strong partisans. In other words, growing cleavages within the Democratic party have made it difficult for the party to establish a clear identity on immigration, and as a consequence, candidates may find it risky to run campaigns with immigration as a central focus. Notably, the growing ideological cleavage among Democrats played out along several issue domains in the 2020 Democratic primaries, as the liberal and moderate wings struggled to

\footnotetext{
${ }^{17}$ It may be that shifts in nationalism, as a result of the September 11th attacks, set the groundwork for downstream shifts in immigration attitudes. Backlash to the Obama presidency may have served as a catalyst.
} 
define the identity of the party.

Within-party differences on politically salient issues may also have potential consequences for party defection and subsequent realignment (Manza and Brooks 1999). With the case of immigration, within-party cleavages among Democrats may explain the oft-discussed "Obama-Trump switchers"-Democrats who voted for Obama in 2012 but subsequently voted for Trump in 2016. If an issue becomes sufficiently salient in the political arena, such as immigration, the possibility emerges for opposing-party candidates to exploit existing cleavages in a party (Hillygus and Shields 2009). Unsatisfied with the liberal, pro-immigration, wing of the Democratic party, more moderate and conservative Democrats may have found the explicit anti-immigration rhetoric appealing in 2016 (Lamont et al. 2017). Further, depending on the continued political saliency of an issue, within-party cleavages may serve as a harbinger of future realignment (Manza and Brooks 1999). Indeed, there is early evidence of this already occurring with immigration: low-educated whites are increasingly identifying as Republicans in recent years, and it is these individuals who demonstrate the most anti-immigration views (Sides et al. 2018; Hajnal and Rivera 2014).

In a highly polarized political environment, within-party variation may have substantial consequences for the implementation of social policies and for political culture, as well. In a two party system, the ability to block increasingly extreme policies from being implemented largely depends on the ability of the opposing party to effectively counter. If intra-party dynamics prevent the opposing party from touting an issue and providing an alternative platform, more extreme, and potentially dangerous, rhetoric and policy proposals can dominate the political arena. While scholars have called for Democrats and left parties in Europe to take ownership of pro-immigration platforms in order to counter the rise of far right parties (Gidrom 2018; Dahlström and Sundell 2012), this paper suggests that intra-party disagreement may be preventing them from doing so.

This paper also has several implications for the literature on mass polarization. I have demonstrated the importance of studying attitudinal trends at three levels (aggregate, between-party, and within-party), but the implications of the results also suggests the continued importance of studying attitudes on select salient issues. Sociologists have shifted their focus from studying polarization on key issues in the public (DiMaggio et al. 1996), to studying issue constraint (Baldassarri and Gelman 2008), to the more recent interest in studying the relationship among a large set of political beliefs (DellaPosta 2020; Baldassarri and Goldberg 2014). Each of these approaches has distinct political implications, and scholars should spell these out. While recent approaches to the study of mass polarization have emphasized the need to go beyond studying a few selected issues, this paper shows the importance of taking a close look at hot-button issues, as they have clear implications for institutional politics (Bélanger and Meguid 2008). Immigration, for instance, became a key issue in the 2016 election and could potentially impact future elections and party alignments (Sides et al. 2018). While more holistic approaches to attitudinal polarization map out important political-cultural developments (DellaPosta 2020; Baldassarri and Goldberg 2014; Baldassarri and Gelman 2008), the implications of these studies give less insight into party coalitions and electoral strategy. Studying salient issues, their relationship to parties, and their role in the political arena, provides sociologists an opportunity to engage more directly with institutional politics and electoral outcomes, topics largely ceded to political scientists in recent decades (Mudge and Chen 2014). 
There are several limitations with the present study. First, a long-term descriptive study of immigration attitudes and their relationship to party could benefit from having an greater number and variety of measures. This study has focused on the commonly used legal immigrant policy item because it covers the largest number of waves and has been shown to be a good measure of Americans' views on the issue (Hainmueller and Hopkins 2014). However, there are other variables that would be important to track over a similar period, such as a feeling thermometer measure toward legal immigrants, as well as illegal immigrants; it is possible that views toward illegal and legal immigrants would trend differently by party (Hainmueller and Hopkins 2014).

Second, while this study traces important descriptive patterns over time, it does not directly contribute to the literature on the causes of attitudes toward immigration. The observed trends are consistent with political party becoming an increasing source of attitudes toward immigration via party signaling and attitude constraint mechanisms - regardless of their relationship to economic vs. cultural socio-tropic concerns (Flores 2018,?; Baldassarri and Gelman 2008); measuring the impact of party signaling on key issues, such as immigration, will remain a vital point of study in future research. Finally, as is often an issue with over-time attitudes studies using cross-sectional data, I cannot determine to what extent trends in between-party attitude differences are due to within-person attitude change, partisan switching, or cohort replacement. However, the importance of measuring between- and within-party cleavages at any given time remains, regardless of potential partisan realignment - the level of disagreement between and within parties at a given time is still of substantive interest.

This paper has brought together sociology research on public opinion with insights from political science on parties and institutional politics. The implications of the findings demonstrate the value of bringing these two literatures together and highlights the importance for the continued revival of research on political parties in sociology (Mudge and Chen 2014). Future studies could apply the analytical approach and methods supplied herein to a wide range of socio-political attitudes of interest to social scientists. For instance, have Democrats become increasingly divided on other issues - such as abortion, welfare, and affirmative action - or is this pattern unique to immigration? Are Republicans increasingly agreeing on issues across the board? Are there similar within-party dynamics in other countries? These are a few possible questions that future studies could answer with the approach and methods outlined in this paper.

\section{References}

Abramowitz, Alan. 2013. The Polarized Public? Why our government is so dysfunctional. Upper Saddle River, NJ: Pearson.

Abramowitz, Alan I and Kyle L Saunders. 1998. "Ideological realignment in the U.S. electorate." Journal of Politics 60:634-652.

Andrews, Wilson and Thomas Kaplan. 2015. "Presidential Candidates on Immigration." The New York Times. 
Baldassarri, Delia and Andrew Gelman. 2008. "Partisans without Constraint: Political Polarization and Trends in American Public Opinion." American Journal of Sociology 114:408-446.

Baldassarri, Delia and Amir Goldberg. 2014. "Neither ideologues nor agnostics: Alternative voters' belief system in an age of Partisan politics." American Journal of Sociology 120:4595.

Bawn, Kathleen, Martin Cohen, David Karol, Seth Masket, Hans Noel, and John Zaller. 2012. "A theory of political parties: Groups, policy demands and nominations in American politics." Perspectives on Politics 10:571-597.

Bélanger, Éric and Bonnie M. Meguid. 2008. "Issue salience, issue ownership, and issue-based vote choice." Electoral Studies 27:477-491.

Berinsky, Adam J. 2009. In Time of War: Understanding American Public Opinion from World War II to Iraq. University of Chicago Press.

Blanco, Maria Narayani Lasala, Robert Y. Shapiro, and Joy Wilke. 2020. "The Nature of Partisan Conflict in Public Opinion: Asymmetric or Symmetric?" American Politics Research pp. 1-13.

Bloemraad, Irene, Fabiana Silva, and Kim Voss. 2016. "Rights, Economics, or Family?Frame Resonance, Political Ideology, and the Immigrant Rights Movement." Social Forces 94:1647-1674.

Bonikowski, Bart and Paul DiMaggio. 2016. "Varieties of American Popular Nationalism." American Sociological Review 81:1-7.

Bonikowski, Bart, Yuval Feinstein, and Sean Bock. 2019. "The Partisan Sorting of "America": How Nationalist Cleavages Shaped the 2016 U.S. Presidential Election." SocArXiv

Brooks, Clem and Jeff Manza. 1997. "Social Cleavages and Political Alignments: U.S. Presidential Elections, 1960 to 1992." American Sociological Review 62:937-946.

Brooks, Clem and Jeff Manza. 2013. "A Broken Public? Americans' Responses to the Great Recession." American Sociological Review 78:727-748.

Dahlström, Carl and Anders Sundell. 2012. "A losing gamble. How mainstream parties facilitate anti-immigrant party success." Electoral Studies 31:353-363.

De Sio, Lorenzo and Till Weber. 2014. "Issue yield: A model of party strategy in multidimensional space." American Political Science Review 108:870-885.

DellaPosta, Daniel. 2020. "Pluralistic Collapse: The "Oil Spill" Model of Mass Opinion Polarization." American Sociological Review 85:507-536.

Dennison, James and Andrew Geddes. 2019. "A rising tide? The salience of immigration and the rise of anti-immigration political parties in Western Europe." Technical Report 1. 
DiMaggio, Paul, John Evans, and Bethany Bryson. 1996. "Have Americans' social attitudes become more polarized?" American Journal of Sociology 102:690-755.

Elliot, Philip and Alex Altman. 2015. "Republican Immigration: 2016 Field Takes Hard Right Turn." Time .

Fiorina, Morris P. and Samuel J. Abrams. 2009. Disconnect: The Breakdown of Representation in American Politics. Norman: University of Oklahoma Press.

Flores, René D. 2017. "Do Anti-Immigrant Laws Shape Public Sentiment? A Study of Arizona's SB 1070 Using Twitter Data 1." Technical report.

Flores, René D. 2018. "Can Elites Shape Public Attitudes Toward Immigrants?: Evidence from the 2016 US Presidential Election." Social Forces 96:1649-1690.

Gidrom, Noam. 2018. "The left shouldn't fear nationalism. It should embrace it." Vox .

Hainmueller, Jens and Daniel J Hopkins. 2014. "Public Attitudes Toward Immigration." Annual Review of Political Science 17:225-249.

Hajnal, Zoltan and Michael U Rivera. 2014. "Immigration, Latinos, and white partisan politics: The new democratic defection." American Journal of Political Science 58:773789.

Hare, Christopher, David A. Armstrong, Ryan Bakker, Royce Carroll, and Keith T Poole. 2015. "Using Bayesian Aldrich-McKelvey Scaling to Study Citizens' Ideological Preferences and Perceptions." American Journal of Political Science 59:759-774.

Hillygus, D Sunshine and Todd G Shields. 2009. The Persuadable Voter. Princeton: Princeton University Press.

Hout, Michael, Clem Brooks, and Jeff Manza. 1995. "The democratic class struggle in the United States, 1948-1992." American Sociological Review 60:805.

Karni, Annie. 2015. "Hillary Clinton 2016: Pivot left on immigration - POLITICO." Politico

Karol, David. 2009. Party position change in American politics: coalition management. Cambridge ; New York: Cambridge University Press.

Lamont, Michèle, Bo Yun Park, and Elena Ayala-Hurtado. 2017. "Trump's electoral speeches and his appeal to the American white working class." The British Journal of Sociology 68:S153-S180.

Layman, Geoffrey C, Thomas M Carsey, and Juliana Menasce Horowitz. 2006. "Party Polarization in American Politics: Characteristics, Causes, and Consequences." Annual Review of Political Science 9:83-110.

Long, J Scott and Sarah A Mustillo. 2018. "Using Predictions and Marginal Effects to Compare Groups in Regression Models for Binary Outcomes." 
Manza, Jeff. and Clem. Brooks. 1999. Social cleavages and political change : voter alignments and US party coalitions. Oxford University Press.

Mason, Lilliana. 2015. "I disrespectfully agree": The differential effects of partisan sorting on social and issue polarization." American Journal of Political Science 59:128-145.

McCarty, Nolan, Keith T. Poole, and Howard Rosenthal. 2008. Polarized America: The Dance of Ideology and Unequal Riches. Cambridge, MA: The MIT Press.

McCarty, Nolan, Keith T Poole, and Howard Rosenthal. 2009. "Does gerrymandering cause polarization?" American Journal of Political Science 53:666-680.

Min Kim, Seung. 2015. "Sanders and immigration? It's complicated." Politico .

Mize, Trenton D. 2019. "Best practices for estimating, interpreting, and presenting nonlinear interaction effects." Sociological Science 6:81-117.

Mize, Trenton D., Long Doan, and J. Scott Long. 2019. "A General Framework for Comparing Predictions and Marginal Effects across Models." Sociological Methodology pp. $1-38$.

Mudge, Stephanie L. and Anthony S. Chen. 2014. "Political parties and the sociological imagination: Past, present, and future directions." Annual Review of Sociology 40:305330.

Mutz, Diana C. 2018. "Status threat, not economic hardship, explains the 2016 presidential vote." Proceedings of the National Academy of Sciences of the United States of America 115:E4330-E4339.

Noel, Hans. 2013. Political Ideologies and Political Parties in America. New York: Cambridge University Press, cambridge edition.

PBS. 2016. "Here's what Clinton and Trump plan on immigration." PBS News Hour .

Petrocik, John R. 1996. "Issue Ownership in Presidential Elections, with a 1980 Case Study." American Journal of Political Science 40:825.

Shor, Boris and Nolan McCarty. 2011. "The ideological mapping of American legislatures." American Political Science Review 105:530-551.

Sides, John, Michael Tesler, and Lynn Vavreck. 2018. Identity crisis : the 2016 presidential campaign and the battle for the meaning of America. Princeton, NJ: Princeton University Press.

The American National Election Studies. 2018. "The ANES Guide to Public Opinion and Electoral Behavior."

Whitehead, Andrew L. and Samuel L. Perry. 2020. Taking America Back for God: Christian Nationalism in the United States. Oxford: Oxford University Press. 
Appendices

\section{Appendix A: Descriptives}

Table 1: Weighted Descriptive Statistics for Each Wave

\begin{tabular}{|c|c|c|c|}
\hline & $\mathrm{N}$ & Mean & SD \\
\hline \multicolumn{4}{|l|}{1992} \\
\hline \multicolumn{4}{|c|}{ Immigration attitudes } \\
\hline Decrease & 2168 & 0.49 & 0.50 \\
\hline Maintain & 2168 & 0.43 & 0.50 \\
\hline Increase & 2168 & 0.08 & 0.27 \\
\hline \multicolumn{4}{|l|}{ Party ID } \\
\hline Democrat & 1497 & 0.59 & 0.49 \\
\hline Republican & 1497 & 0.41 & 0.49 \\
\hline \multicolumn{4}{|l|}{ Political Ideology } \\
\hline Liberal & 1824 & 0.28 & 0.45 \\
\hline Moderate & 1824 & 0.32 & 0.46 \\
\hline Conservative & 1824 & 0.41 & 0.49 \\
\hline \multicolumn{4}{|l|}{ Education } \\
\hline Less than HS & 2420 & 0.08 & 0.27 \\
\hline $\mathrm{HS}$ & 2420 & 0.46 & 0.50 \\
\hline Some College & 2420 & 0.23 & 0.42 \\
\hline BA or more & 2420 & 0.23 & 0.42 \\
\hline Age & 2484 & 45.82 & 17.89 \\
\hline Male & 2485 & 0.46 & 0.50 \\
\hline \multicolumn{4}{|l|}{ Income } \\
\hline 0 to $33 \%$ & 2281 & 0.34 & 0.47 \\
\hline 34 to $67 \%$ & 2281 & 0.30 & 0.46 \\
\hline 68 to $100 \%$ & 2281 & 0.36 & 0.48 \\
\hline \multicolumn{4}{|l|}{ Region } \\
\hline Northeast & 2485 & 0.19 & 0.39 \\
\hline North Central & 2485 & 0.27 & 0.44 \\
\hline South & 2485 & 0.35 & 0.48 \\
\hline West & 2485 & 0.19 & 0.39 \\
\hline \multicolumn{4}{|c|}{ Religious tradition } \\
\hline Protestant & 2467 & 0.56 & 0.50 \\
\hline Catholic & 2467 & 0.24 & 0.42 \\
\hline Jewish & 2467 & 0.02 & 0.14 \\
\hline Other and none & 2467 & 0.18 & 0.39 \\
\hline Religiosity & 2295 & 0.78 & 0.41 \\
\hline \multicolumn{4}{|c|}{ Church attendance } \\
\hline Never & 2472 & 0.37 & 0.48 \\
\hline Occasional & 2472 & 0.29 & 0.45 \\
\hline
\end{tabular}




\begin{tabular}{|c|c|c|c|}
\hline Regular & 2472 & 0.34 & 0.47 \\
\hline \multicolumn{4}{|l|}{1994} \\
\hline \multicolumn{4}{|c|}{ Immigration attitudes } \\
\hline Decrease & 1730 & 0.66 & 0.47 \\
\hline Maintain & 1730 & 0.28 & 0.45 \\
\hline Increase & 1730 & 0.05 & 0.22 \\
\hline \multicolumn{4}{|l|}{ Party ID } \\
\hline Democrat & 1152 & 0.53 & 0.50 \\
\hline Republican & 1152 & 0.47 & 0.50 \\
\hline \multicolumn{4}{|c|}{ Political Ideology } \\
\hline Liberal & 1400 & 0.19 & 0.39 \\
\hline Moderate & 1400 & 0.34 & 0.47 \\
\hline Conservative & 1400 & 0.47 & 0.50 \\
\hline \multicolumn{4}{|l|}{ Education } \\
\hline Less than HS & 1757 & 0.06 & 0.23 \\
\hline HS & 1757 & 0.49 & 0.50 \\
\hline Some College & 1757 & 0.25 & 0.44 \\
\hline BA or more & 1757 & 0.20 & 0.40 \\
\hline Age & 1795 & 44.06 & 17.35 \\
\hline Male & 1795 & 0.48 & 0.50 \\
\hline \multicolumn{4}{|l|}{ Income } \\
\hline 0 to $33 \%$ & 1649 & 0.32 & 0.46 \\
\hline 34 to $67 \%$ & 1649 & 0.35 & 0.48 \\
\hline 68 to $100 \%$ & 1649 & 0.34 & 0.47 \\
\hline \multicolumn{4}{|l|}{ Region } \\
\hline Northeast & 1795 & 0.17 & 0.37 \\
\hline North Central & 1795 & 0.27 & 0.44 \\
\hline South & 1795 & 0.37 & 0.48 \\
\hline West & 1795 & 0.19 & 0.39 \\
\hline \multicolumn{4}{|c|}{ Religious tradition } \\
\hline Protestant & 1768 & 0.53 & 0.50 \\
\hline Catholic & 1768 & 0.25 & 0.43 \\
\hline Jewish & 1768 & 0.02 & 0.13 \\
\hline Other and none & 1768 & 0.20 & 0.40 \\
\hline Religiosity & 1760 & 0.77 & 0.42 \\
\hline \multicolumn{4}{|c|}{ Church attendance } \\
\hline Never & 1769 & 0.39 & 0.49 \\
\hline Occasional & 1769 & 0.29 & 0.45 \\
\hline Regular & 1769 & 0.33 & 0.47 \\
\hline \multicolumn{4}{|c|}{1996} \\
\hline \multicolumn{4}{|c|}{ Immigration attitudes } \\
\hline Decrease & 1499 & 0.59 & 0.49 \\
\hline Maintain & 1499 & 0.36 & 0.48 \\
\hline
\end{tabular}




\begin{tabular}{lccc}
\hline Increase & 1499 & 0.05 & 0.23 \\
Party ID & & & \\
Democrat & 1133 & 0.59 & 0.49 \\
Republican & 1133 & 0.41 & 0.49 \\
Political Ideology & & & \\
Liberal & 1329 & 0.24 & 0.43 \\
Moderate & 1329 & 0.32 & 0.47 \\
Conservative & 1329 & 0.44 & 0.50 \\
Education & & & \\
Less than HS & 1711 & 0.05 & 0.21 \\
HS & 1711 & 0.47 & 0.50 \\
Some College & 1711 & 0.27 & 0.44 \\
BA or more & 1711 & 0.22 & 0.41 \\
Age & 1712 & 44.61 & 17.39 \\
Male & 1714 & 0.46 & 0.50 \\
Income & & & \\
0 to 33\% & 1564 & 0.33 & 0.47 \\
34 to 67\% & 1564 & 0.37 & 0.48 \\
68 to 100\% & 1564 & 0.30 & 0.46 \\
Region & & & \\
Northeast & 1714 & 0.16 & 0.37 \\
North Central & 1714 & 0.26 & 0.44 \\
South & 1714 & 0.38 & 0.49 \\
West & 1714 & 0.19 & 0.39 \\
Religious tradition & & & \\
Protestant & 1710 & 0.53 & 0.50 \\
Catholic & 1710 & 0.26 & 0.44 \\
Jewish & 1710 & 0.02 & 0.12 \\
Other and none & 1710 & 0.20 & 0.40 \\
Religiosity & 1706 & 0.78 & 0.41 \\
Church attendance & & & \\
Never & 1705 & 0.37 & 0.48 \\
Occasional & 1705 & 0.34 & 0.47 \\
Regular & 1705 & 0.30 & 0.46 \\
\hline 1998 & & & \\
Immigration attitudes & & & \\
Decrease & 1245 & 0.51 & 0.50 \\
Maintain & 1245 & 0.39 & 0.49 \\
Increase & 1245 & 0.11 & 0.31 \\
Party ID & & & \\
Democrat & 810 & 0.59 & 0.49 \\
Republican & 810 & 0.41 & 0.49 \\
Political Ideology & & & \\
\hline & & & \\
\hline
\end{tabular}




\begin{tabular}{lccc}
\hline Liberal & 1018 & 0.24 & 0.43 \\
Moderate & 1018 & 0.37 & 0.48 \\
Conservative & 1018 & 0.39 & 0.49 \\
Education & & & \\
Less than HS & 1276 & 0.06 & 0.23 \\
HS & 1276 & 0.44 & 0.50 \\
Some College & 1276 & 0.28 & 0.45 \\
BA or more & 1276 & 0.23 & 0.42 \\
Age & 1265 & 45.20 & 17.52 \\
Male & 1281 & 0.46 & 0.50 \\
Income & & & \\
0 to 33\% & 1219 & 0.33 & 0.47 \\
34 to 67\% & 1219 & 0.34 & 0.47 \\
68 to 100\% & 1219 & 0.34 & 0.47 \\
Region & & & \\
Northeast & 1281 & 0.19 & 0.39 \\
North Central & 1281 & 0.25 & 0.43 \\
South & 1281 & 0.38 & 0.48 \\
West & 1281 & 0.19 & 0.39 \\
Religious tradition & & & \\
Protestant & 1274 & 0.47 & 0.50 \\
Catholic & 1274 & 0.31 & 0.46 \\
Jewish & 1274 & 0.02 & 0.14 \\
Other and none & 1274 & 0.20 & 0.40 \\
Religiosity & 1270 & 0.77 & 0.42 \\
Church attendance & & & \\
Never & 1271 & 0.37 & 0.48 \\
Occasional & 1271 & 0.30 & 0.46 \\
Regular & 1271 & 0.33 & 0.47 \\
\hline 2000 & & & \\
Immigration attitudes & & & \\
Decrease & 1742 & 0.47 & 0.50 \\
Maintain & 1742 & 0.44 & 0.50 \\
Increase & 1742 & 0.09 & 0.28 \\
Party ID & & & \\
Democrat & 1069 & 0.59 & 0.49 \\
Republican & 1069 & 0.41 & 0.49 \\
Political Ideology & & & \\
Liberal & 673 & 0.27 & 0.44 \\
Moderate & 673 & 0.31 & 0.46 \\
Conservative & 673 & 0.42 & 0.49 \\
Education & & & \\
Less than HS & 1800 & 0.04 & 0.20 \\
\hline & & & \\
\hline
\end{tabular}




\begin{tabular}{|c|c|c|c|}
\hline HS & 1800 & 0.44 & 0.50 \\
\hline Some College & 1800 & 0.28 & 0.45 \\
\hline BA or more & 1800 & 0.24 & 0.43 \\
\hline Age & 1798 & 45.55 & 17.64 \\
\hline Male & 1807 & 0.44 & 0.50 \\
\hline \multicolumn{4}{|l|}{ Income } \\
\hline 0 to $33 \%$ & 1515 & 0.39 & 0.49 \\
\hline 34 to $67 \%$ & 1515 & 0.30 & 0.46 \\
\hline 68 to $100 \%$ & 1515 & 0.31 & 0.46 \\
\hline \multicolumn{4}{|l|}{ Region } \\
\hline Northeast & 1807 & 0.19 & 0.40 \\
\hline North Central & 1807 & 0.25 & 0.43 \\
\hline South & 1807 & 0.36 & 0.48 \\
\hline West & 1807 & 0.20 & 0.40 \\
\hline \multicolumn{4}{|c|}{ Religious tradition } \\
\hline Protestant & 1787 & 0.52 & 0.50 \\
\hline Catholic & 1787 & 0.27 & 0.44 \\
\hline Jewish & 1787 & 0.02 & 0.14 \\
\hline Other and none & 1787 & 0.19 & 0.40 \\
\hline Religiosity & 1799 & 0.76 & 0.43 \\
\hline \multicolumn{4}{|c|}{ Church attendance } \\
\hline Never & 1789 & 0.36 & 0.48 \\
\hline Occasional & 1789 & 0.31 & 0.46 \\
\hline Regular & 1789 & 0.33 & 0.47 \\
\hline \multicolumn{4}{|l|}{2004} \\
\hline \multicolumn{4}{|c|}{ Immigration attitudes } \\
\hline Decrease & 1047 & 0.48 & 0.50 \\
\hline Maintain & 1047 & 0.43 & 0.49 \\
\hline Increase & 1047 & 0.10 & 0.30 \\
\hline \multicolumn{4}{|l|}{ Party ID } \\
\hline Democrat & 726 & 0.53 & 0.50 \\
\hline Republican & 726 & 0.47 & 0.50 \\
\hline \multicolumn{4}{|c|}{ Political Ideology } \\
\hline Liberal & 920 & 0.25 & 0.43 \\
\hline Moderate & 920 & 0.33 & 0.47 \\
\hline Conservative & 920 & 0.41 & 0.49 \\
\hline \multicolumn{4}{|l|}{ Education } \\
\hline Less than HS & 1212 & 0.05 & 0.21 \\
\hline HS & 1212 & 0.41 & 0.49 \\
\hline Some College & 1212 & 0.29 & 0.45 \\
\hline BA or more & 1212 & 0.26 & 0.44 \\
\hline Age & 1212 & 46.54 & 17.57 \\
\hline Male & 1212 & 0.49 & 0.50 \\
\hline
\end{tabular}




\begin{tabular}{|c|c|c|c|}
\hline \multicolumn{4}{|l|}{ Income } \\
\hline 0 to $33 \%$ & 1070 & 0.35 & 0.48 \\
\hline 34 to $67 \%$ & 1070 & 0.30 & 0.46 \\
\hline 68 to $100 \%$ & 1070 & 0.35 & 0.48 \\
\hline \multicolumn{4}{|l|}{ Region } \\
\hline Northeast & 1212 & 0.20 & 0.40 \\
\hline North Central & 1212 & 0.25 & 0.44 \\
\hline South & 1212 & 0.35 & 0.48 \\
\hline West & 1212 & 0.20 & 0.40 \\
\hline \multicolumn{4}{|c|}{ Religious tradition } \\
\hline Protestant & 1209 & 0.49 & 0.50 \\
\hline Catholic & 1209 & 0.25 & 0.43 \\
\hline Jewish & 1209 & 0.03 & 0.16 \\
\hline Other and none & 1209 & 0.23 & 0.42 \\
\hline Religiosity & 1203 & 0.77 & 0.42 \\
\hline \multicolumn{4}{|c|}{ Church attendance } \\
\hline Never & 1204 & 0.35 & 0.48 \\
\hline Occasional & 1204 & 0.30 & 0.46 \\
\hline Regular & 1204 & 0.35 & 0.48 \\
\hline \multicolumn{4}{|l|}{2008} \\
\hline \multicolumn{4}{|c|}{ Immigration attitudes } \\
\hline Decrease & 2061 & 0.45 & 0.50 \\
\hline Maintain & 2061 & 0.41 & 0.49 \\
\hline Increase & 2061 & 0.14 & 0.35 \\
\hline \multicolumn{4}{|l|}{ Party ID } \\
\hline Democrat & 1403 & 0.57 & 0.50 \\
\hline Republican & 1403 & 0.43 & 0.50 \\
\hline \multicolumn{4}{|c|}{ Political Ideology } \\
\hline Liberal & 1626 & 0.29 & 0.45 \\
\hline Moderate & 1626 & 0.29 & 0.45 \\
\hline Conservative & 1626 & 0.42 & 0.49 \\
\hline \multicolumn{4}{|l|}{ Education } \\
\hline Less than HS & 2308 & 0.02 & 0.15 \\
\hline HS & 2308 & 0.41 & 0.49 \\
\hline Some College & 2308 & 0.29 & 0.45 \\
\hline BA or more & 2308 & 0.28 & 0.45 \\
\hline Age & 2277 & 46.85 & 17.72 \\
\hline Male & 2322 & 0.45 & 0.50 \\
\hline \multicolumn{4}{|l|}{ Income } \\
\hline 0 to $33 \%$ & 2139 & 0.31 & 0.46 \\
\hline 34 to $67 \%$ & 2139 & 0.39 & 0.49 \\
\hline 68 to $100 \%$ & 2139 & 0.30 & 0.46 \\
\hline Region & & & \\
\hline
\end{tabular}




\begin{tabular}{|c|c|c|c|}
\hline Northeast & 2322 & 0.15 & 0.35 \\
\hline North Central & 2322 & 0.21 & 0.41 \\
\hline South & 2322 & 0.43 & 0.49 \\
\hline West & 2322 & 0.21 & 0.41 \\
\hline \multicolumn{4}{|c|}{ Religious tradition } \\
\hline Protestant & 2320 & 0.53 & 0.50 \\
\hline Catholic & 2320 & 0.19 & 0.39 \\
\hline Jewish & 2320 & 0.01 & 0.12 \\
\hline Other and none & 2320 & 0.27 & 0.44 \\
\hline Religiosity & 2309 & 0.71 & 0.45 \\
\hline \multicolumn{4}{|c|}{ Church attendance } \\
\hline Never & 2315 & 0.33 & 0.47 \\
\hline Occasional & 2315 & 0.29 & 0.45 \\
\hline Regular & 2315 & 0.38 & 0.49 \\
\hline \multicolumn{4}{|l|}{2012} \\
\hline \multicolumn{4}{|c|}{ Immigration attitudes } \\
\hline Decrease & 5390 & 0.44 & 0.50 \\
\hline Maintain & 5390 & 0.42 & 0.49 \\
\hline Increase & 5390 & 0.14 & 0.35 \\
\hline \multicolumn{4}{|l|}{ Party ID } \\
\hline Democrat & 3741 & 0.56 & 0.50 \\
\hline Republican & 3741 & 0.44 & 0.50 \\
\hline \multicolumn{4}{|l|}{ Political Ideology } \\
\hline Liberal & 5300 & 0.26 & 0.44 \\
\hline Moderate & 5300 & 0.34 & 0.48 \\
\hline Conservative & 5300 & 0.40 & 0.49 \\
\hline \multicolumn{4}{|l|}{ Education } \\
\hline Less than HS & 5846 & 0.02 & 0.14 \\
\hline $\mathrm{HS}$ & 5846 & 0.38 & 0.49 \\
\hline Some College & 5846 & 0.30 & 0.46 \\
\hline BA or more & 5846 & 0.29 & 0.46 \\
\hline Age & 5852 & 47.38 & 17.38 \\
\hline Male & 5914 & 0.48 & 0.50 \\
\hline \multicolumn{4}{|l|}{ Income } \\
\hline 0 to $33 \%$ & 5715 & 0.31 & 0.46 \\
\hline 34 to $67 \%$ & 5715 & 0.37 & 0.48 \\
\hline 68 to $100 \%$ & 5715 & 0.31 & 0.46 \\
\hline \multicolumn{4}{|l|}{ Region } \\
\hline Northeast & 5914 & 0.17 & 0.38 \\
\hline North Central & 5914 & 0.22 & 0.41 \\
\hline South & 5914 & 0.38 & 0.49 \\
\hline West & 5914 & 0.23 & 0.42 \\
\hline Religious traditio & & & \\
\hline
\end{tabular}




\begin{tabular}{|c|c|c|c|}
\hline Protestant & 5895 & 0.42 & 0.49 \\
\hline Catholic & 5895 & 0.22 & 0.41 \\
\hline Jewish & 5895 & 0.02 & 0.14 \\
\hline Other and none & 5895 & 0.35 & 0.48 \\
\hline Religiosity & 5882 & 0.67 & 0.47 \\
\hline \multicolumn{4}{|c|}{ Church attendance } \\
\hline Never & 5880 & 0.33 & 0.47 \\
\hline Occasional & 5880 & 0.25 & 0.43 \\
\hline Regular & 5880 & 0.43 & 0.50 \\
\hline \multicolumn{4}{|l|}{2016} \\
\hline Decrease & 3621 & 0.44 & 0.50 \\
\hline Maintain & 3621 & 0.40 & 0.49 \\
\hline Increase & 3621 & 0.16 & 0.37 \\
\hline \multicolumn{4}{|l|}{ Party ID } \\
\hline Democrat & 2678 & 0.55 & 0.50 \\
\hline Republican & 2678 & 0.45 & 0.50 \\
\hline \multicolumn{4}{|c|}{ Political Ideology } \\
\hline Liberal & 3049 & 0.32 & 0.47 \\
\hline Moderate & 3049 & 0.29 & 0.45 \\
\hline Conservative & 3049 & 0.39 & 0.49 \\
\hline \multicolumn{4}{|l|}{ Education } \\
\hline Less than HS & 4231 & 0.01 & 0.11 \\
\hline $\mathrm{HS}$ & 4231 & 0.37 & 0.48 \\
\hline Some College & 4231 & 0.31 & 0.46 \\
\hline BA or more & 4231 & 0.31 & 0.46 \\
\hline Age & 4149 & 47.31 & 17.65 \\
\hline Male & 4218 & 0.48 & 0.50 \\
\hline \multicolumn{4}{|l|}{ Income } \\
\hline 0 to $33 \%$ & 4157 & 0.32 & 0.47 \\
\hline 34 to $67 \%$ & 4157 & 0.30 & 0.46 \\
\hline 68 to $100 \%$ & 4157 & 0.38 & 0.49 \\
\hline \multicolumn{4}{|l|}{ Region } \\
\hline Northeast & 4270 & 0.18 & 0.38 \\
\hline North Central & 4270 & 0.22 & 0.41 \\
\hline South & 4270 & 0.38 & 0.48 \\
\hline West & 4270 & 0.23 & 0.42 \\
\hline \multicolumn{4}{|c|}{ Religious tradition } \\
\hline Protestant & 4269 & 0.43 & 0.50 \\
\hline Catholic & 4269 & 0.22 & 0.41 \\
\hline Jewish & 4269 & 0.02 & 0.13 \\
\hline Other and none & 4269 & 0.33 & 0.47 \\
\hline Religiosity & 4243 & 0.65 & 0.48 \\
\hline
\end{tabular}




\begin{tabular}{llll}
\hline Church attendance & & & \\
Never & 4248 & 0.30 & 0.46 \\
Occasional & 4248 & 0.28 & 0.45 \\
Regular & 4248 & 0.42 & 0.49 \\
\hline
\end{tabular}


Figure 9: Over-time compositions for Democrats and Republicans. Plots display weighted proportions of each group over time (Source: ANES).

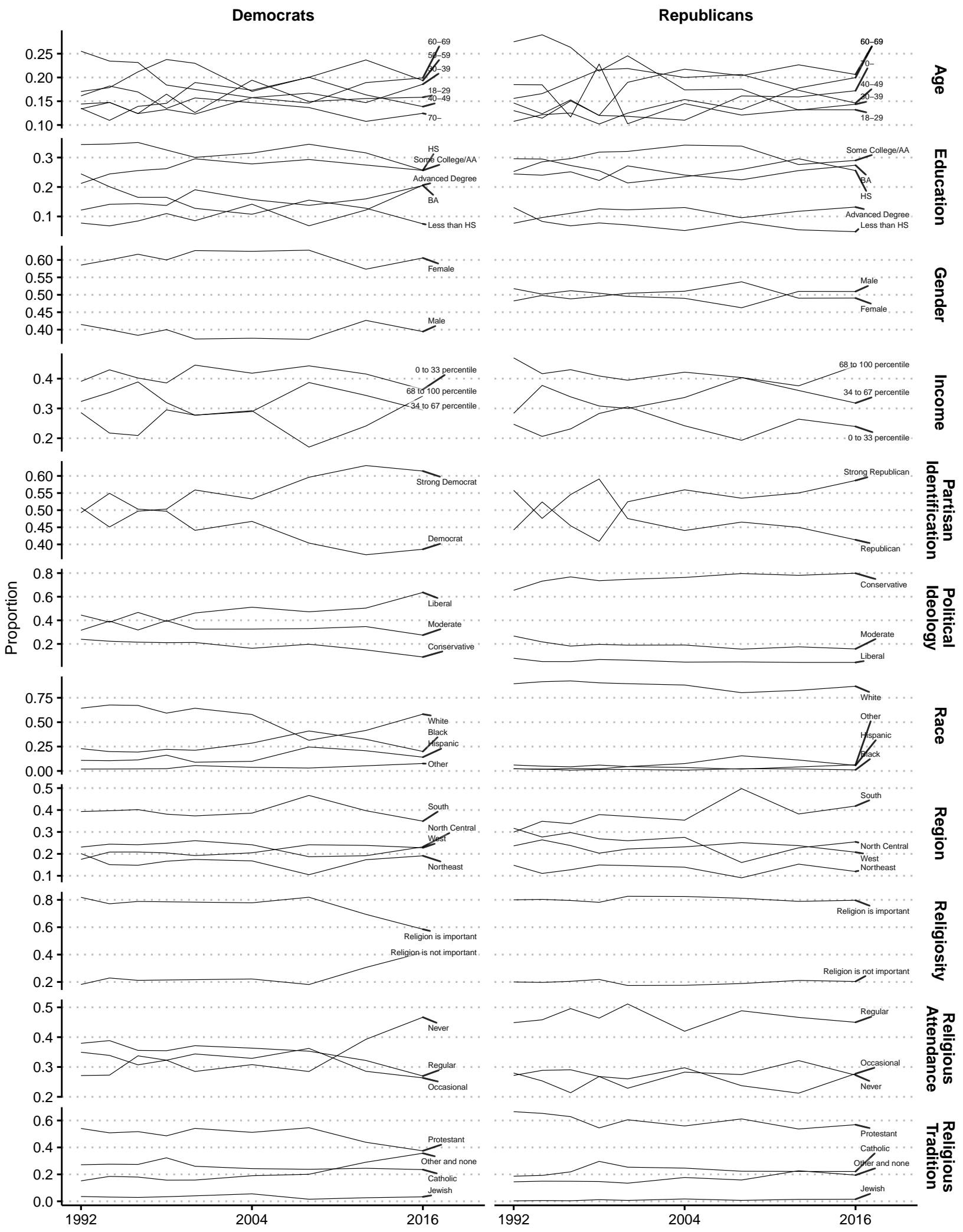




\section{Appendix B: Regression tables}

This appendix includes tables for the regression results, which are displayed graphically in the results section. Table 2 displays results for the over-time, between-party, and withinparty models. I also display a "Full" model, which presents results with all variables included and no interactions. The results are displayed as logits (log-odds). As the graphical displays in the results section plot predictions, I present the results here as logits to include both predicted values (which are preferred for cross-model comparisons and interactions [Mize 2019; Mize et al. 2019]) and logit coefficients, which are estimated parameters from the ordinal logit model. I do not include tabular results for each variableXyear interaction model because this would result in twenty-four (12 variables X 2 parties) columns of results. Results for these models are available upon request. Table 3 presents tabular results from the variance function regression. The first column $(\beta)$ contains OLS coefficients; the second column $(\lambda)$ contains variance coefficients.

Table 2: Logits for ordinal logistic regressions predicting immigration attitudes. Model "Over time" includes only sample year. "Party x Year" includes party identification and a partyXyear interaction. The "Full" model includes all covariates. Models "Democrats" and "Republicans" include models with covariates, restricted to only Democrats and Republicans, respectively (full model interactions)

\begin{tabular}{|c|c|c|c|c|c|}
\hline & \multicolumn{3}{|c|}{ Full sample models } & \multicolumn{2}{|c|}{ Party-specific Models } \\
\hline & Over time & Party $\times$ Year & Full & Democrats & Republicans \\
\hline 1992 & Ref & Ref & Ref & Ref & Ref \\
\hline 1994 & $\begin{array}{c}-0.633^{* * *} \\
(0.064)\end{array}$ & $\begin{array}{c}-0.719^{* * *} \\
(0.109)\end{array}$ & $\begin{array}{c}-0.529^{* * *} \\
(0.101)\end{array}$ & $\begin{array}{c}-0.616^{* * *} \\
(0.140)\end{array}$ & $\begin{array}{c}-0.463^{* *} \\
(0.145)\end{array}$ \\
\hline 1996 & $\begin{array}{c}-0.345^{* * *} \\
(0.065)\end{array}$ & $\begin{array}{c}-0.441^{* * *} \\
(0.106)\end{array}$ & $\begin{array}{c}-0.336^{* * *} \\
(0.101)\end{array}$ & $\begin{array}{c}-0.546^{* * *} \\
(0.137)\end{array}$ & $\begin{array}{l}-0.115 \\
(0.148)\end{array}$ \\
\hline 1998 & $\begin{array}{c}0.033 \\
(0.068)\end{array}$ & $\begin{array}{l}-0.008 \\
(0.112)\end{array}$ & $\begin{array}{c}0.041 \\
(0.105)\end{array}$ & $\begin{array}{c}-0.083 \\
(0.141)\end{array}$ & $\begin{array}{c}0.226 \\
(0.158)\end{array}$ \\
\hline 2000 & $\begin{array}{c}0.151^{*} \\
(0.061)\end{array}$ & $\begin{array}{c}0.120 \\
(0.103)\end{array}$ & $\begin{array}{c}0.117 \\
(0.125)\end{array}$ & $\begin{array}{c}0.090 \\
(0.170)\end{array}$ & $\begin{array}{c}0.129 \\
(0.186)\end{array}$ \\
\hline 2004 & $\begin{array}{c}0.098 \\
(0.071)\end{array}$ & $\begin{array}{c}0.079 \\
(0.127)\end{array}$ & $\begin{array}{c}0.176 \\
(0.114)\end{array}$ & $\begin{array}{c}-0.012 \\
(0.163)\end{array}$ & $\begin{array}{c}0.298 \\
(0.160)\end{array}$ \\
\hline 2008 & $\begin{array}{c}0.304^{* * *} \\
(0.059)\end{array}$ & $\begin{array}{c}0.202^{*} \\
(0.095)\end{array}$ & $\begin{array}{l}0.320^{* *} \\
(0.097)\end{array}$ & $\begin{array}{c}0.226 \\
(0.129)\end{array}$ & $\begin{array}{l}0.475^{* *} \\
(0.151)\end{array}$ \\
\hline 2012 & $\begin{array}{c}0.314^{* * *} \\
(0.048)\end{array}$ & $\begin{array}{c}0.459^{* * *} \\
(0.080)\end{array}$ & $\begin{array}{l}0.218^{* *} \\
(0.078)\end{array}$ & $\begin{array}{l}0.278^{* *} \\
(0.105)\end{array}$ & $\begin{array}{c}0.120 \\
(0.119)\end{array}$ \\
\hline 2016 & $\begin{array}{c}0.310^{* * *} \\
(0.052)\end{array}$ & $\begin{array}{c}0.876^{* * *} \\
(0.088)\end{array}$ & $\begin{array}{c}0.200^{*} \\
(0.083)\end{array}$ & $\begin{array}{c}0.642^{* * *} \\
(0.114)\end{array}$ & $\begin{array}{c}-0.346^{* *} \\
(0.125)\end{array}$ \\
\hline
\end{tabular}




\begin{tabular}{|c|c|c|c|c|c|}
\hline & \multicolumn{3}{|c|}{ Full sample models } & \multicolumn{2}{|c|}{ Party-specific Models } \\
\hline & Over time & Party $\times$ Year & Full & Democrats & Republicans \\
\hline Democrat & & Ref & Ref & & \\
\hline Republican & & $\begin{array}{l}-0.272^{*} \\
(0.107)\end{array}$ & $\begin{array}{c}-0.316^{* * *} \\
(0.057)\end{array}$ & & \\
\hline $1992 \times$ Democrat & & Ref & & & \\
\hline $1992 \times$ Republican & & Ref & & & \\
\hline $1994 \times$ Democrat & & Ref & & & \\
\hline $1994 \times$ Republican & & $\begin{array}{c}0.130 \\
(0.165)\end{array}$ & & & \\
\hline $1996 \times$ Democrat & & Ref & & & \\
\hline $1996 \times$ Republican & & $\begin{array}{c}0.215 \\
(0.165)\end{array}$ & & & \\
\hline $1998 \times$ Democrat & & Ref & & & \\
\hline $1998 \times$ Republican & & $\begin{array}{c}0.125 \\
(0.175)\end{array}$ & & & \\
\hline $2000 \times$ Democrat & & Ref & & & \\
\hline $2000 \times$ Republican & & $\begin{array}{c}0.037 \\
(0.160)\end{array}$ & & & \\
\hline $2004 \times$ Democrat & & Ref & & & \\
\hline $2004 \times$ Republican & & $\begin{array}{c}0.033 \\
(0.185)\end{array}$ & & & \\
\hline $2008 \times$ Democrat & & Ref & & & \\
\hline $2008 \times$ Republican & & $\begin{array}{c}0.154 \\
(0.158)\end{array}$ & & & \\
\hline $2012 \times$ Democrat & & Ref & & & \\
\hline
\end{tabular}




\begin{tabular}{|c|c|c|c|c|c|}
\hline & \multicolumn{3}{|c|}{ Full sample models } & \multicolumn{2}{|c|}{ Party-specific Models } \\
\hline & Over time & Party $\times$ Year & Full & Democrats & Republicans \\
\hline $2012 \times$ Republican & & $\begin{array}{c}-0.381^{* *} \\
(0.127)\end{array}$ & & & \\
\hline $2016 \times$ Democrat & & Ref & & & \\
\hline $2016 \times$ Republican & & $\begin{array}{c}-1.266^{* * *} \\
(0.136)\end{array}$ & & & \\
\hline $18-29$ & & & Ref & Ref & Ref \\
\hline $30-39$ & & & $\begin{array}{c}-0.195^{* *} \\
(0.071)\end{array}$ & $\begin{array}{c}-0.417^{* * *} \\
(0.095)\end{array}$ & $\begin{array}{c}0.084 \\
(0.110)\end{array}$ \\
\hline $40-49$ & & & $\begin{array}{c}-0.318^{* * *} \\
(0.072)\end{array}$ & $\begin{array}{c}-0.498^{* * *} \\
(0.096)\end{array}$ & $\begin{array}{l}-0.053 \\
(0.113)\end{array}$ \\
\hline $50-59$ & & & $\begin{array}{c}-0.368^{* * *} \\
(0.072)\end{array}$ & $\begin{array}{c}-0.595^{* * *} \\
(0.096)\end{array}$ & $\begin{array}{l}-0.076 \\
(0.112)\end{array}$ \\
\hline $60-69$ & & & $\begin{array}{c}-0.232^{* *} \\
(0.075)\end{array}$ & $\begin{array}{c}-0.426^{* * *} \\
(0.100)\end{array}$ & $\begin{array}{c}-0.021 \\
(0.118)\end{array}$ \\
\hline $70-$ & & & $\begin{array}{c}-0.296^{* * *} \\
(0.080)\end{array}$ & $\begin{array}{c}-0.448^{* * *} \\
(0.110)\end{array}$ & $\begin{array}{l}-0.070 \\
(0.121)\end{array}$ \\
\hline Male & & & $\begin{array}{c}0.081 \\
(0.041)\end{array}$ & $\begin{array}{c}0.047 \\
(0.055)\end{array}$ & $\begin{array}{l}0.182^{* *} \\
(0.064)\end{array}$ \\
\hline 0 to 33 percentile & & & Ref & Ref & Ref \\
\hline 34 to 67 percentile & & & $\begin{array}{l}-0.076 \\
(0.053)\end{array}$ & $\begin{array}{l}-0.060 \\
(0.067)\end{array}$ & $\begin{array}{l}-0.083 \\
(0.088)\end{array}$ \\
\hline 68 to 100 percentile & & & $\begin{array}{l}0.159^{* *} \\
(0.058)\end{array}$ & $\begin{array}{c}0.186^{*} \\
(0.077)\end{array}$ & $\begin{array}{c}0.116 \\
(0.091)\end{array}$ \\
\hline Less than HS & & & Ref & Ref & Ref \\
\hline $\mathrm{HS}$ & & & $\begin{array}{l}-0.155 \\
(0.084)\end{array}$ & $\begin{array}{c}-0.242^{*} \\
(0.101)\end{array}$ & $\begin{array}{c}-0.070 \\
(0.159)\end{array}$ \\
\hline Some College/AA & & & $\begin{array}{c}0.008 \\
(0.085)\end{array}$ & $\begin{array}{l}-0.016 \\
(0.103)\end{array}$ & $\begin{array}{l}-0.016 \\
(0.159)\end{array}$ \\
\hline $\mathrm{BA}$ & & & $\begin{array}{c}0.458^{* * *} \\
(0.090)\end{array}$ & $\begin{array}{c}0.516^{* * *} \\
(0.113)\end{array}$ & $\begin{array}{c}0.348^{*} \\
(0.163)\end{array}$ \\
\hline
\end{tabular}




\begin{tabular}{|c|c|c|c|c|c|}
\hline & \multicolumn{3}{|c|}{ Full sample models } & \multicolumn{2}{|c|}{ Party-specific Models } \\
\hline & Over time & Party $\times$ Year & Full & Democrats & Republicans \\
\hline Advanced Degree & & & $\begin{array}{c}0.723^{* * *} \\
(0.098)\end{array}$ & $\begin{array}{c}0.745^{* * *} \\
(0.122)\end{array}$ & $\begin{array}{l}0.558^{* *} \\
(0.175)\end{array}$ \\
\hline Northeast & & & Ref & Ref & Ref \\
\hline North Central & & & $\begin{array}{c}-0.039 \\
(0.067)\end{array}$ & $\begin{array}{c}-0.196^{*} \\
(0.088)\end{array}$ & $\begin{array}{c}0.186 \\
(0.107)\end{array}$ \\
\hline South & & & $\begin{array}{l}-0.102 \\
(0.063)\end{array}$ & $\begin{array}{l}-0.131 \\
(0.082)\end{array}$ & $\begin{array}{c}0.014 \\
(0.103)\end{array}$ \\
\hline West & & & $\begin{array}{c}0.004 \\
(0.067)\end{array}$ & $\begin{array}{l}-0.108 \\
(0.087)\end{array}$ & $\begin{array}{c}0.201 \\
(0.109)\end{array}$ \\
\hline Protestant & & & Ref & Ref & Ref \\
\hline Catholic & & & $\begin{array}{c}0.083 \\
(0.054)\end{array}$ & $\begin{array}{c}0.048 \\
(0.074)\end{array}$ & $\begin{array}{c}0.130 \\
(0.079)\end{array}$ \\
\hline Jewish & & & $\begin{array}{c}0.851^{* * *} \\
(0.134)\end{array}$ & $\begin{array}{c}0.832^{* * *} \\
(0.153)\end{array}$ & $\begin{array}{c}0.799^{* *} \\
(0.300)\end{array}$ \\
\hline Other and none & & & $\begin{array}{c}0.291^{\text {*** }} \\
(0.061)\end{array}$ & $\begin{array}{l}0.243^{* *} \\
(0.080)\end{array}$ & $\begin{array}{l}0.310^{* *} \\
(0.095)\end{array}$ \\
\hline Religion is not important & & & Ref & Ref & Ref \\
\hline Religion is important & & & $\begin{array}{l}-0.072 \\
(0.058)\end{array}$ & $\begin{array}{l}-0.084 \\
(0.075)\end{array}$ & $\begin{array}{c}0.083 \\
(0.096)\end{array}$ \\
\hline Regular & & & Ref & Ref & Ref \\
\hline Occasional & & & $\begin{array}{c}-0.324^{* * *} \\
(0.053)\end{array}$ & $\begin{array}{c}-0.274^{* * *} \\
(0.072)\end{array}$ & $\begin{array}{c}-0.345^{* * *} \\
(0.079)\end{array}$ \\
\hline Never & & & $\begin{array}{c}-0.230^{* * *} \\
(0.061)\end{array}$ & $\begin{array}{l}-0.167^{*} \\
(0.082)\end{array}$ & $\begin{array}{c}-0.294^{* *} \\
(0.095)\end{array}$ \\
\hline White & & & Ref & Ref & Ref \\
\hline Black & & & $\begin{array}{c}0.159^{*} \\
(0.070)\end{array}$ & $\begin{array}{c}0.049 \\
(0.079)\end{array}$ & $\begin{array}{c}0.693^{* *} \\
(0.258)\end{array}$ \\
\hline Hispanic & & & $\begin{array}{c}0.586^{* * *} \\
(0.071)\end{array}$ & $\begin{array}{c}0.539^{* * *} \\
(0.089)\end{array}$ & $\begin{array}{c}0.659^{* * *} \\
(0.125)\end{array}$ \\
\hline
\end{tabular}




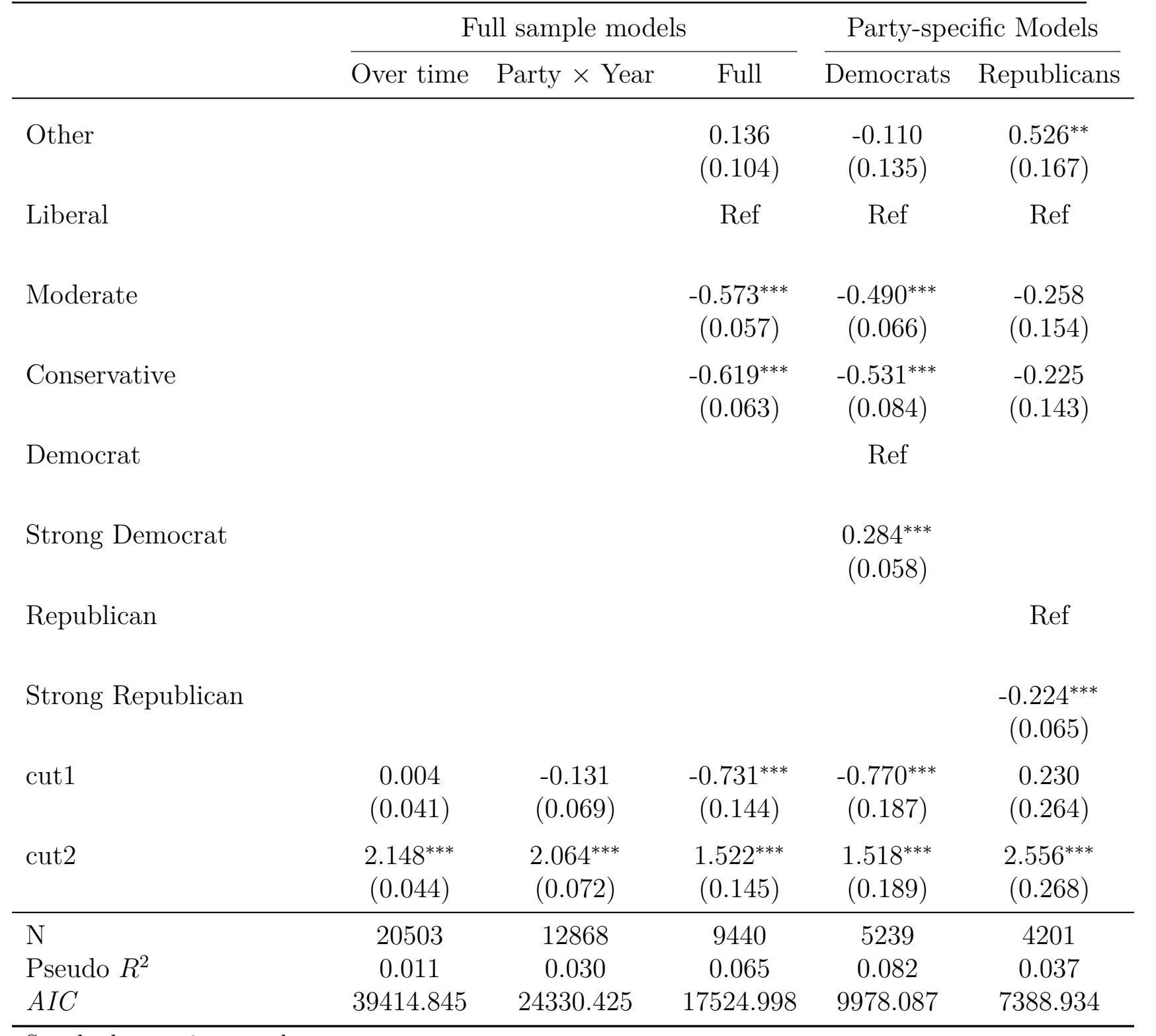

Standard errors in parentheses

${ }^{*} p<0.05,{ }^{* *} p<0.01,{ }^{* * *} p<0.001$ 
Table 3: Results from a variance function regression predicting immigration attitudes. First column reports beta coefficients $(\beta)$. Second column reports lambda coefficients $(\lambda)$.

\begin{tabular}{|c|c|c|}
\hline & $\beta$ & $\lambda$ \\
\hline 1992 & Ref & Ref \\
\hline 1994 & $\begin{array}{c}-0.222^{* * *} \\
(0.034)\end{array}$ & $\begin{array}{c}-0.153^{*} \\
(0.065)\end{array}$ \\
\hline 1996 & $\begin{array}{c}-0.149^{* * *} \\
(0.035)\end{array}$ & $\begin{array}{c}-0.143^{*} \\
(0.065)\end{array}$ \\
\hline 1998 & $\begin{array}{c}0.002 \\
(0.039)\end{array}$ & $\begin{array}{c}0.044 \\
(0.070)\end{array}$ \\
\hline 2000 & $\begin{array}{c}0.040 \\
(0.036)\end{array}$ & $\begin{array}{l}-0.009 \\
(0.065)\end{array}$ \\
\hline 2004 & $\begin{array}{c}0.039 \\
(0.046)\end{array}$ & $\begin{array}{c}0.136 \\
(0.079)\end{array}$ \\
\hline 2008 & $\begin{array}{c}0.083^{*} \\
(0.034)\end{array}$ & $\begin{array}{l}0.168^{* *} \\
(0.059)\end{array}$ \\
\hline 2012 & $\begin{array}{c}0.172^{* * *} \\
(0.028)\end{array}$ & $\begin{array}{l}0.147^{* *} \\
(0.050)\end{array}$ \\
\hline 2016 & $\begin{array}{c}0.327^{* * *} \\
(0.032)\end{array}$ & $\begin{array}{r}0.230^{* * *} \\
(0.055)\end{array}$ \\
\hline Democrat & Ref & Ref \\
\hline Republican & $\begin{array}{c}-0.101^{* *} \\
(0.035)\end{array}$ & $\begin{array}{c}-0.151^{*} \\
(0.067)\end{array}$ \\
\hline $1992 \times$ Democrat & Ref & Ref \\
\hline $1992 \times$ Republican & Ref & Ref \\
\hline $1994 \times$ Democrat & Ref & Ref \\
\hline 1994 × Republican & $\begin{array}{c}0.057 \\
(0.050)\end{array}$ & $\begin{array}{c}0.038 \\
(0.097)\end{array}$ \\
\hline $1996 \times$ Democrat & Ref & Ref \\
\hline
\end{tabular}




\begin{tabular}{|c|c|c|}
\hline & $\beta$ & $\lambda$ \\
\hline 1996 × Republican & $\begin{array}{c}0.077 \\
(0.052)\end{array}$ & $\begin{array}{c}0.070 \\
(0.101)\end{array}$ \\
\hline $1998 \times$ Democrat & Ref & Ref \\
\hline $1998 \times$ Republican & $\begin{array}{c}0.051 \\
(0.060)\end{array}$ & $\begin{array}{c}0.126 \\
(0.109)\end{array}$ \\
\hline $2000 \times$ Democrat & Ref & Ref \\
\hline $2000 \times$ Republican & $\begin{array}{c}0.016 \\
(0.054)\end{array}$ & $\begin{array}{c}0.083 \\
(0.100)\end{array}$ \\
\hline $2004 \times$ Democrat & Ref & Ref \\
\hline $2004 \times$ Republican & $\begin{array}{c}0.001 \\
(0.063)\end{array}$ & $\begin{array}{c}-0.083 \\
(0.115)\end{array}$ \\
\hline $2008 \times$ Democrat & Ref & Ref \\
\hline $2008 \times$ Republican & $\begin{array}{c}0.059 \\
(0.056)\end{array}$ & $\begin{array}{c}0.129 \\
(0.098)\end{array}$ \\
\hline $2012 \times$ Democrat & Ref & Ref \\
\hline $2012 \times$ Republican & $\begin{array}{c}-0.133^{* *} \\
(0.042)\end{array}$ & $\begin{array}{l}-0.000 \\
(0.079)\end{array}$ \\
\hline $2016 \times$ Democrat & Ref & Ref \\
\hline $2016 \times$ Republican & $\begin{array}{c}-0.430^{* * *} \\
(0.045)\end{array}$ & $\begin{array}{c}-0.194^{*} \\
(0.083)\end{array}$ \\
\hline Constant & $\begin{array}{c}1.640^{* * *} \\
(0.024)\end{array}$ & $\begin{array}{c}-0.846^{* * *} \\
(0.043)\end{array}$ \\
\hline $\begin{array}{l}\mathrm{N} \\
A I C\end{array}$ & $\begin{array}{c}12868 \\
25729.974\end{array}$ & $\begin{array}{c}12868 \\
4391.710\end{array}$ \\
\hline
\end{tabular}

Standard errors in parentheses

${ }^{*} p<0.05,{ }^{* *} p<0.01,{ }^{* * *} p<0.001$ 


\section{Appendix C: Variance function robustness check}

The overall substantive conclusions do not change whether a three- or five-outcome immigration attitude measure is used. As one would expect, the overall levels of variance are larger with the five-outcome variable, compared to the three-outcome coding (Figure 10). One noticeable difference is the flatter trend between 2008 and 2016 when using the five-outcome coding. Further, while the 2012 difference between Republicans and Democrats is significant with the three-outcome coding, it is not with the five.

Figure 10: Variance function regression results with three- and five-outcome immigration attitude variable. Left panel presents over-time predicted logged variance results for both versions of outcome. Right panel displays over-time average discrete changes for Republicans compared to Democrats on predicted logged variance. Dashed lines indicate $95 \%$ confidence intervals; dashed lines crossing the solid horizontal line indicates that there is no significant difference between Republicans and Democrats in terms of their respective predicted variance in that year.
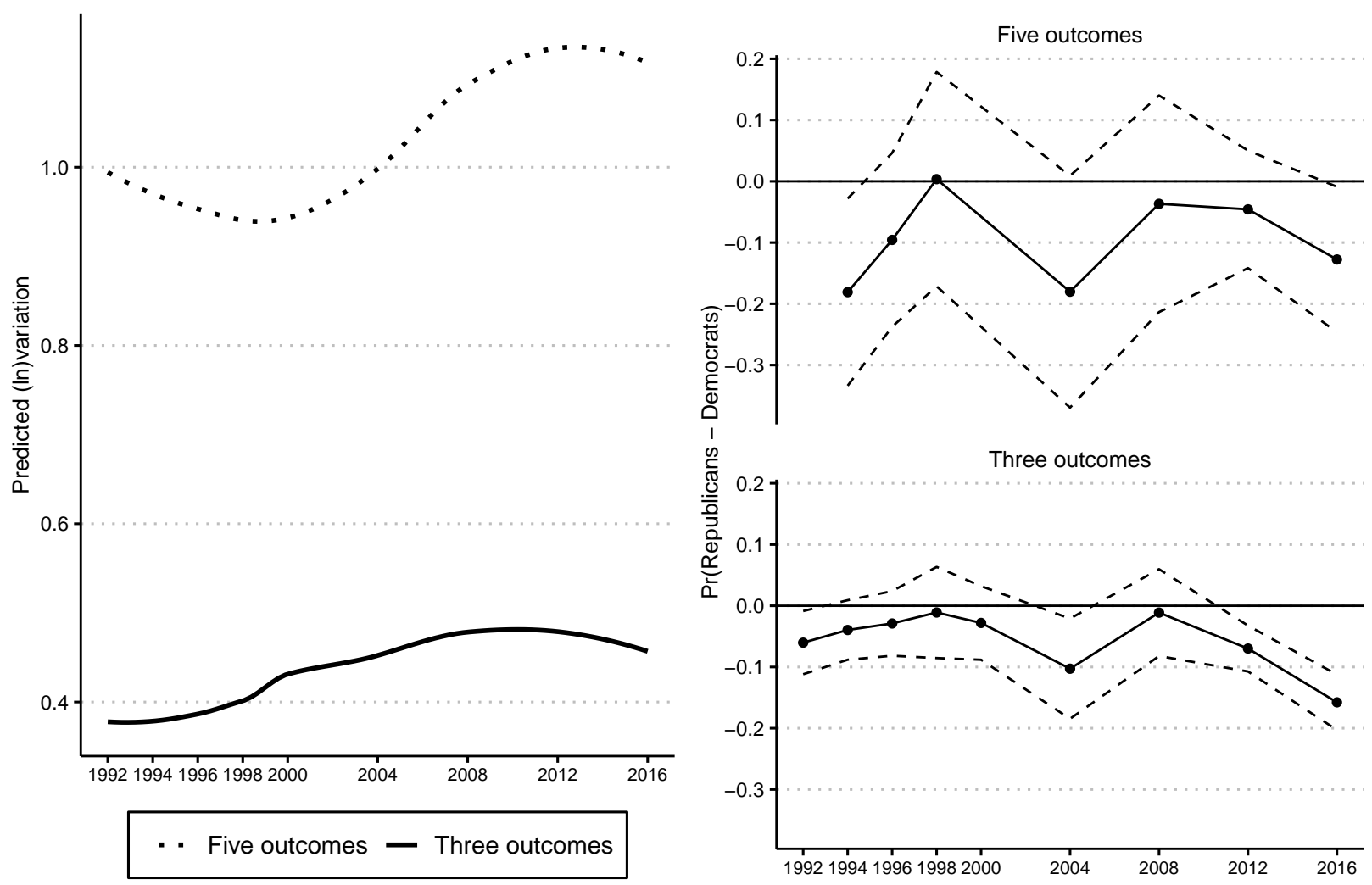
Figure 11 illustrates the over-time trends for both parties with the five-outcome coding. The minor differences we see among Republicans in the variance function analysis appears to result from nonparallel trends with the two anti-immigration categories. Indeed, most of the over-time change among anti-immigration Republicans has been due to changes among those with strong anti-immigration sentiment. This appears to explain both the differences in the early 1990s and the latter two waves. The collapsing of categories does not affect the variance function results among Democrats as much, because pro- and anti-immigration pairs trend fairly parallel.

Figure 11: Over-time party trends with five-outcome coding

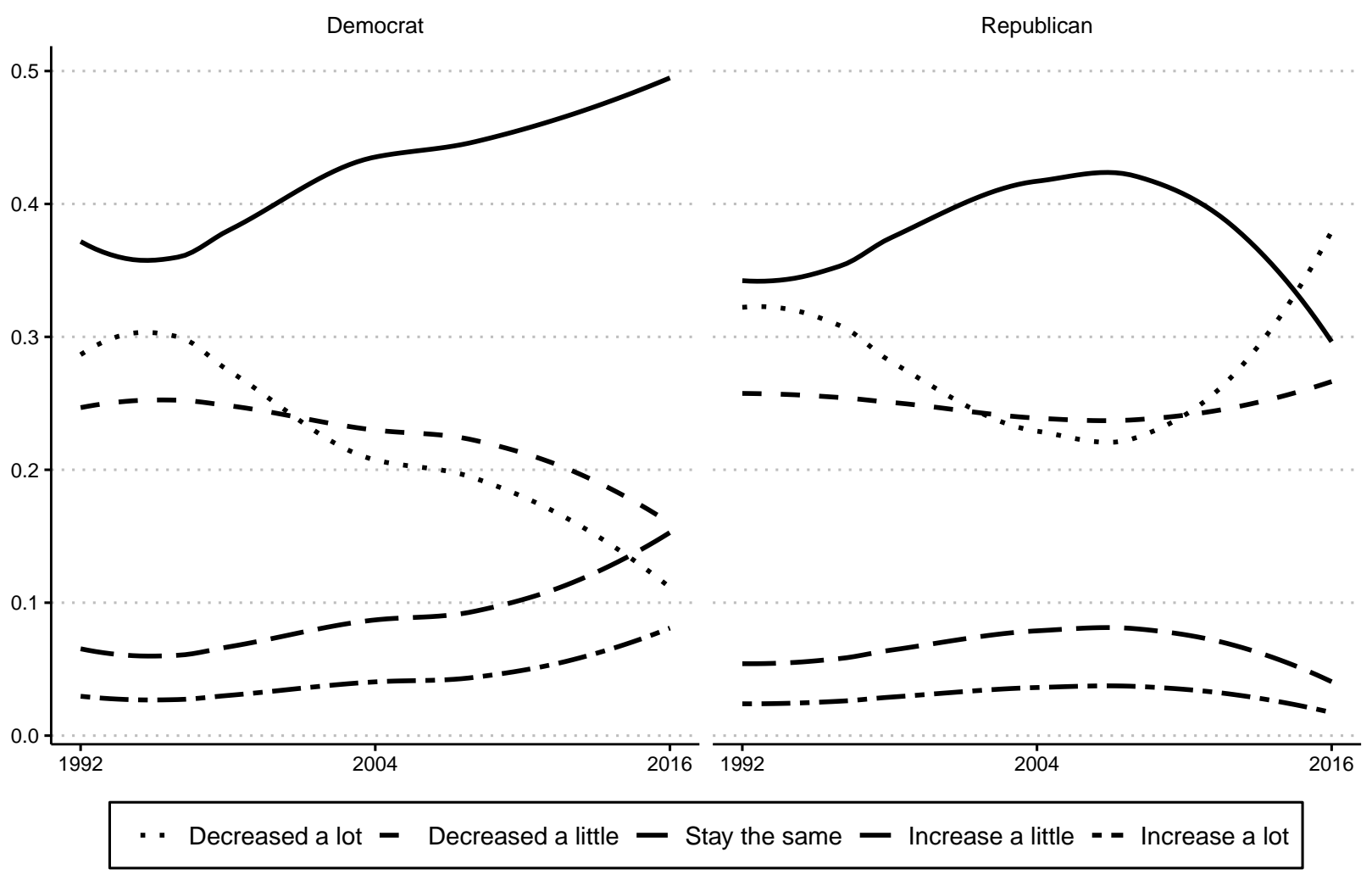

Appendix D: Over-time trends for $\kappa^{\prime}$ 
Figure 12: Within-party cleavages over time. Smoothed over-time trend lines for $\kappa^{\prime}$ indices for Democrats and Republicans.

\section{Democrats}

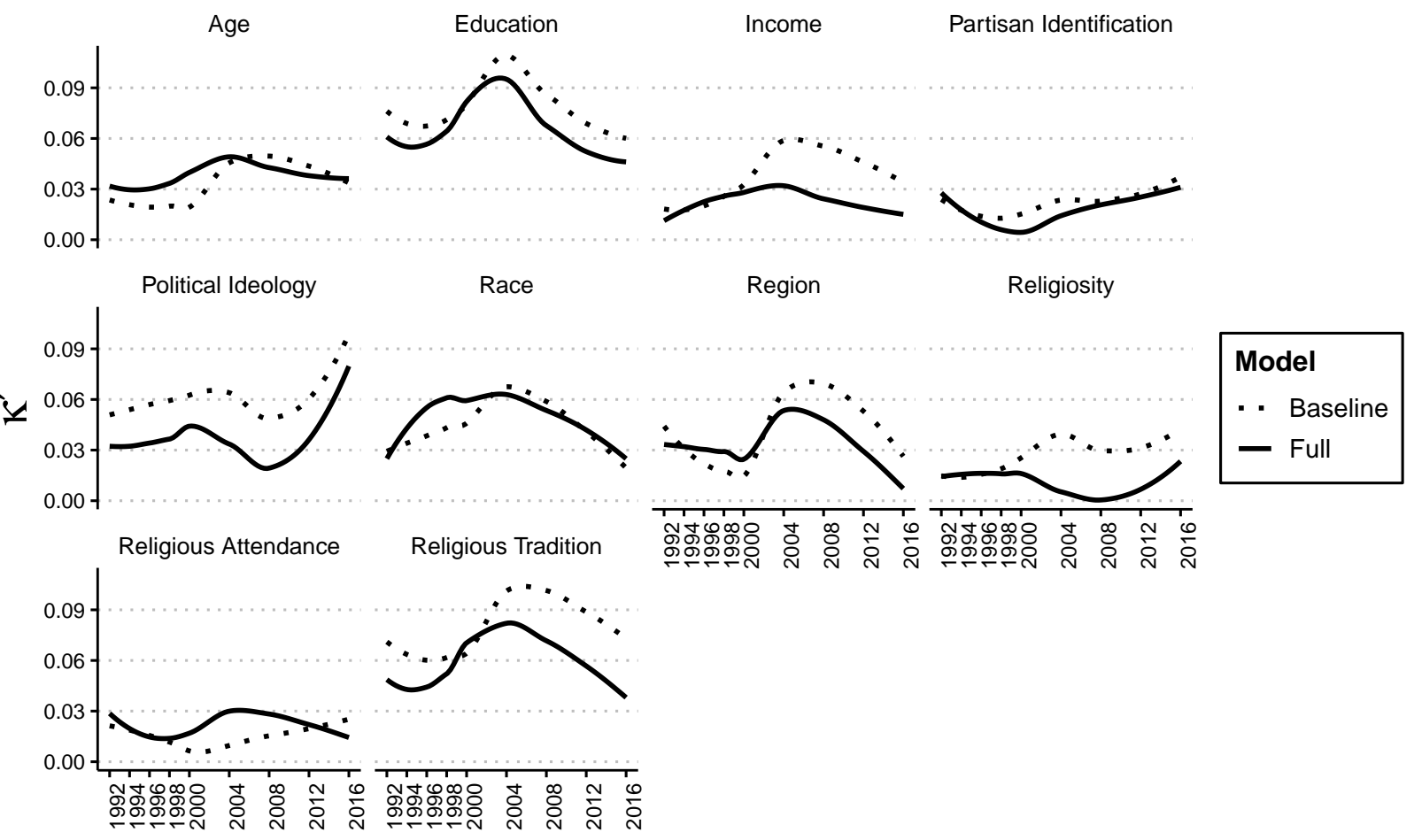

\section{Republicans}

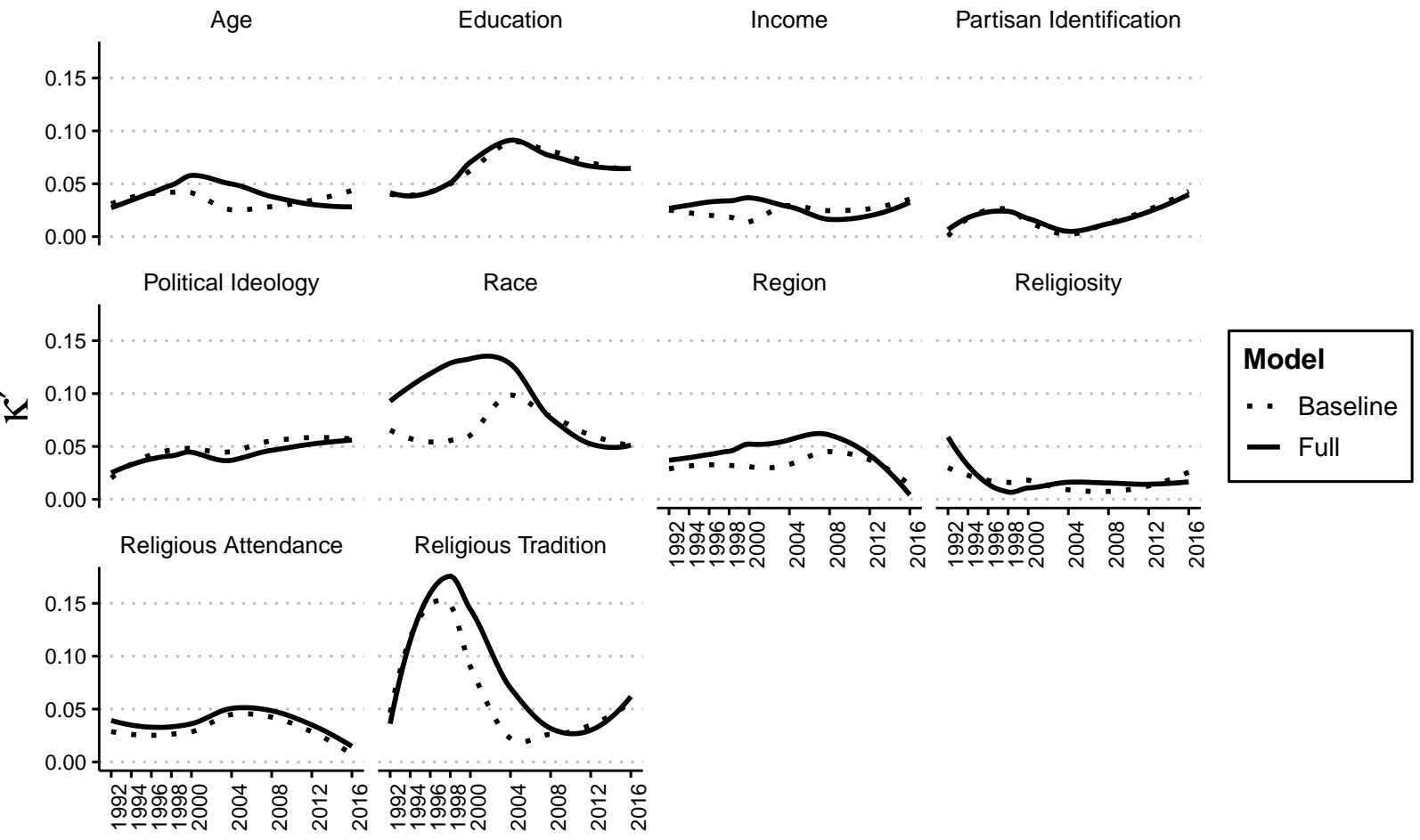

